\title{
Dementia diagnostics in primary care
}

with a focus on cognitive testing

\section{Anna Segernäs Kvitting}

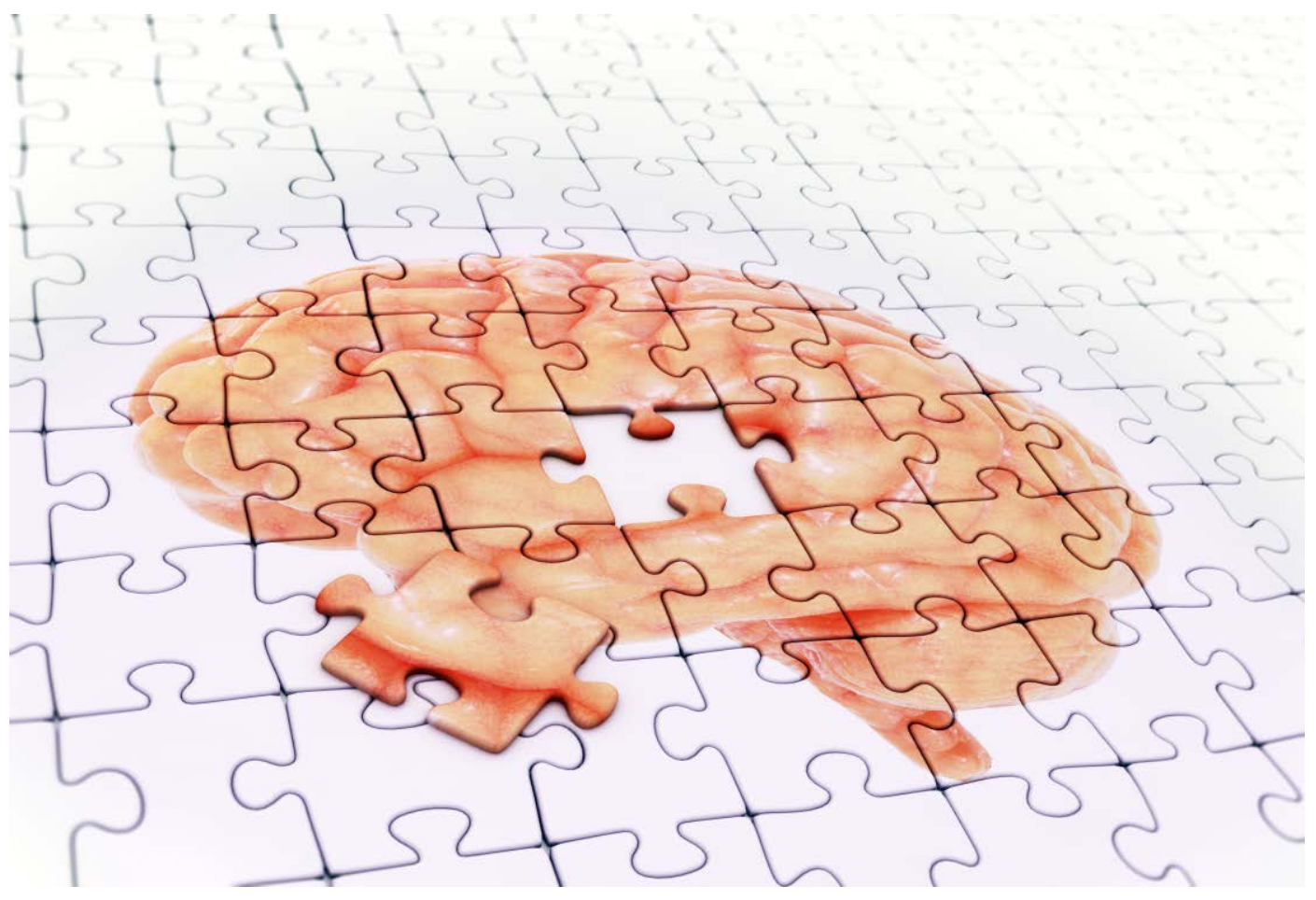




\section{Dementia diagnostics in primary care} with a focus on cognitive testing

Anna Segernäs Kvitting

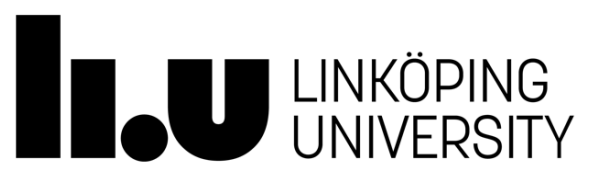

Department of Medical and Health Sciences

Linköping University, Sweden

Linköping 2019 
(CAnna Segernäs Kvitting, 2019

Cover picture: Picture from Shutterstock images. Printed with permission.

Published articles have been reprinted with the permission of the copyright holders.

Printed in Sweden by LiU-Tryck, Linköping, Sweden, 2019

ISSN 0345-0082

ISBN 978-91-7685-037-4 
To Astrid, Vera and Vilgot

To go fast, go alone.

To go far, go together.

African proverb 



\section{CONTENTS}

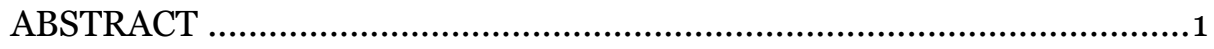

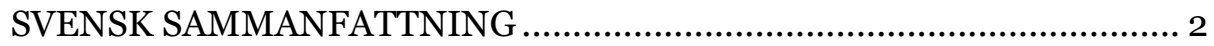

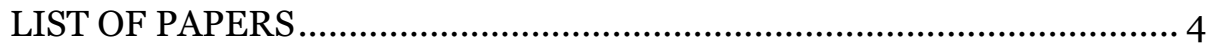

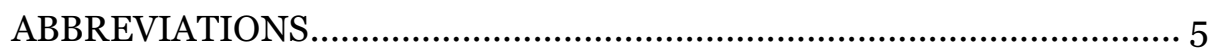

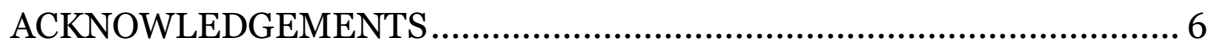

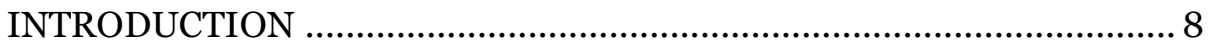

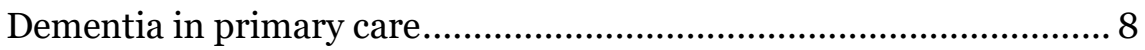

Risk factors for dementia ................................................................... 9

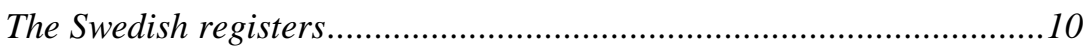

Demography ............................................................................11

Social burden and economical cost ..................................................12

Cognitive impairment........................................................................13

Mild cognitive impairment (minor neurocognitive disorder) ..................13

Dementia (major neurocognitive disorder)...........................................14

The role of the general practitioner and primary care ..........................15

Brief history of Swedish primary health care.........................................15

The multiprofessional team in dementia care ........................................16

GPS' role in dementia diagnostic procedures .......................................17

Dementia assessments in primary care .............................................. 17

Basic dementia investigations ..............................................................17

Cognitive tests in dementia assessments in primary care........................18

Early diagnosis of dementia versus normal ageing.................................19

Tests of executive function and motor speed ...........................................20

Dementia diagnosis in a multi-cultural population ..................................21

Differential diagnosis of dementia in primary care ...............................22

RATIONALE FOR THE THESIS ......................................................... 24

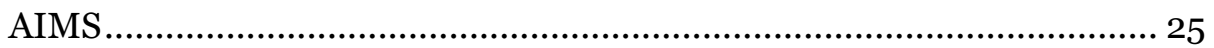




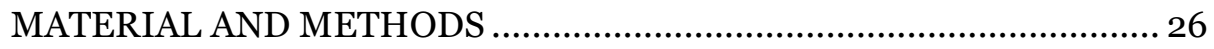

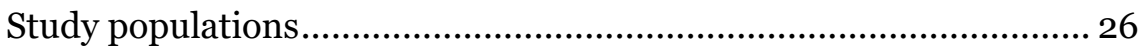

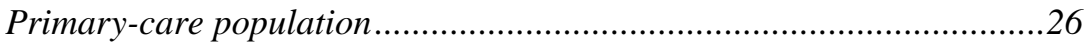

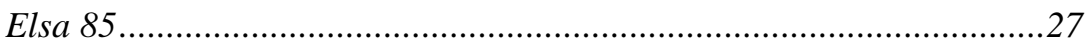

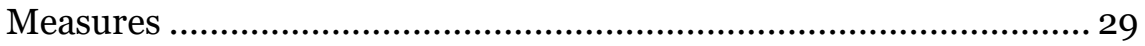

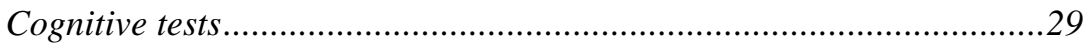

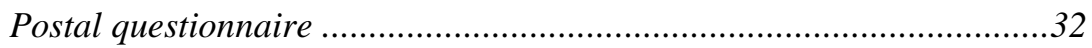

EQ-5D

Statistical analysis ......................................................................... 33

Ethical considerations ….............................................................. 34

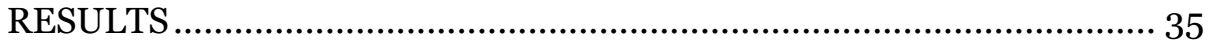

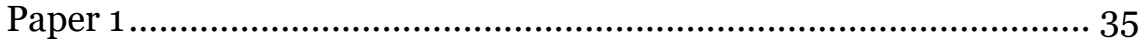

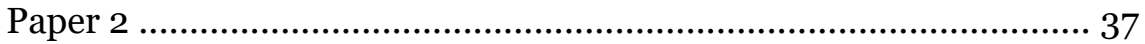

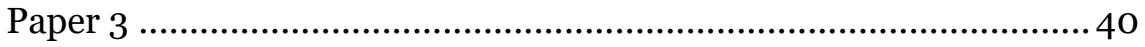

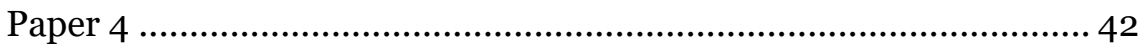

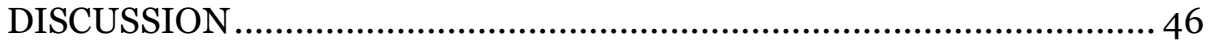

General findings …........................................................................... 47

A Quick Test of cognitive speed............................................................4

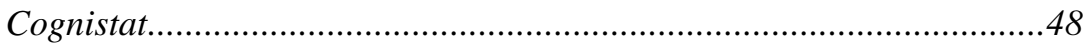

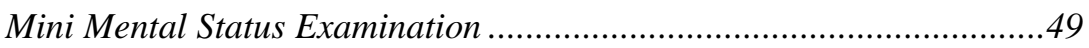

Cognitive Assessment Battery............................................................50

Methodological considerations............................................................5

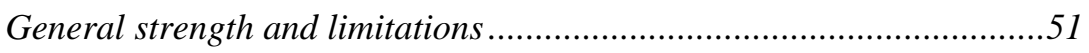

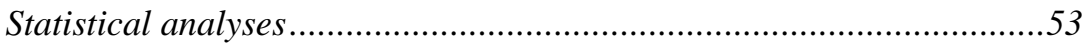

Diagnostic considerations ...................................................................5

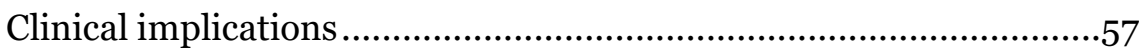

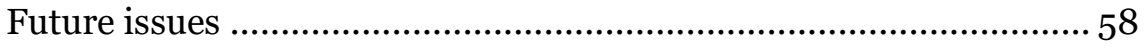

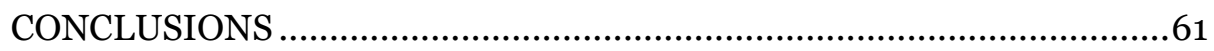

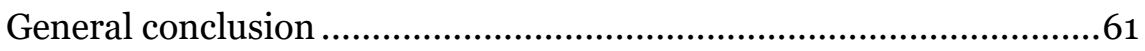

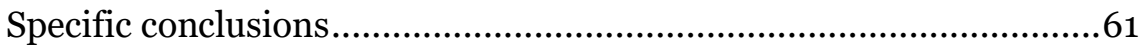

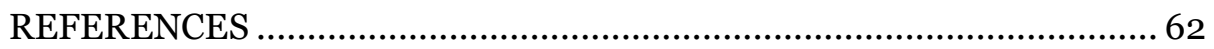




\section{ABSTRACT}

\section{Background}

Age is the greatest risk factor for developing dementia and the total number of people aged 60 years and above is expected to more than double globally from 2013 to 2050 (1). Primary health care (PHC) is important for basic diagnostic evaluations. Objective test measurements have been shown to be more reliable than a patient's subjective memory complaints in dementia assessments (2). However, several studies indicate the low use of objective cognitive screening tools in dementia diagnostics in PHC (3). Some general practitioners (GPs) do not perceive today's cognitive instruments as helpful in the diagnostic process and administration problems have been reported in $\mathrm{PHC}(4,5)$.

The overall aim of this thesis was to investigate the accuracy of several cognitive tests used in dementia assessments in PHC, especially among older patients: A Quick Test of Cognitive Speed (AQT), Cognistat and Cognitive Assessment Battery (CAB). The normative values of the Mini Mental Status Examination (MMSE) in the oldest old was also studied.

\section{Methods}

The studies included in this thesis are from two different study populations.

- Studies I, II and IV. Patients with and without cognitive symptoms were recruited from four primary health care centres in Sweden between 2007 and 2009.

- Study III. The Elderly in Linköping Screening Assessment (ELSA 85) cohort-population examined people born in 1922 in the municipality of Linköping, Sweden.

\section{Results}

Study I. Results showed that AQT is a usable test for dementia diagnosis in PHC. Sensitivity for AQT is superior to the Clock Drawing Test (CDT), equivalent to MMSE and the combination MMSE and CDT. The AUC for AQT was 0.773, valued good enough.

Study II. Overall, the results for Cognistat in this study are superior to MMSE and CDT, also in combination. Cognistat is promising for improved dementia diagnosis in PHC with a quick and easily administered multi-domain test for dementia assessments.

Study III. This study presents valuable information about normative MMSE data for the oldest patients. Results, suggest using the $25^{\text {th }}$ percentile in MMSE of 25 to 26 points, and indicate that MMSE 26 is as a reasonable cut-off for cognitive decline and further medical evaluation in older persons aged from 85 to 93 years.

Study IV. In summary, the additive value of the CAB test in dementia investigations in PHC is not obvious. In addition to questionable accuracy, the test is quite time consuming and normative values are scarce. By introducing the numerical sum (CABsum) the accuracy was increased.

\section{Conclusion}

In conclusion, objective cognitive tests are an important part of dementia diagnosis in PHC and there is a need for improved instruments and norm-values. From our results, several cognitive quick tests are usable in PHC - MMSE, AQT and Cognistat - but they have some disadvantages. MMSE 26 is a reasonable cut-off for cognitive decline in the oldest patients 85 to 93 years from a well-educated population with quite good socioeconomic. There is a great interest in finding short and better multi-domain instruments but the additive value of $\mathrm{CAB}$ in dementia investigations in $\mathrm{PHC}$ is questionable. 


\section{SVENSK SAMMANFATTNING}

Ålder är den huvudsakliga riskfaktorn för att utveckla demenssjukdom. Antalet äldre (över 60 år) förväntas mer än fördubblas globalt mellan åren 2013 to 2050. Demenssjukdom medför tidigt stora konsekvenser för de drabbade och primärvården är viktig i den basala demensutredningen. Någon botande medicinering för demenssjukdom finns idag inte. Tidig och korrekt diagnostik av demenssjukdom är ändå betydelsefull då det möjligör att rätt stödinsatser sätts in till patienter och anhöriga och att patienter kan få symtomlindrande behandling under sjukdomsförloppet.

Objektiv kognitiv testning har visats vara mer tillförlitlig än patienters beskrivna subjektiva minnessvårigheter i utredning och diagnostik av demenssjukdom. Flera studier har trots detta visat på underanvändning av objektiva kognitiva tester inom primärvården. Tidigare studier har också beskrivit att specialister i allmänmedicin uttrycker tveksamhet till vad de kognitiva testerna tillför i diagnostiken och hur testerna används på vårdcentralerna.

Basal demensutredning består enligt de Nationella riktlinjerna för vård och omsorg vid demenssjukdom av flera insatser där kognitiv testning är en del. Utöver testning är det viktigt med ett läkarbesök för medicinsk och psykiatrisk undersökning, datortomografi av hjärnan för att också utesluta andra möjliga underliggande sjukdomar, relevant blodprovstagning, omvårdnadsanamnes och en aktivitetsbedömning av en arbetsterapeut.

Det övergripande syftet med avhandlingsarbetet är att undersöka träffsäkerheten och tillförlitligheten i några av de kognitiva tester som används vid demensdiagnostik inom primärvården, särskilt i den äldre populationen: A Quick Test of Cognitive Speed (AQT), Cognistat och Kognitiva Screeningbatteriet (KSB). Vi har också undersökt normativa värden och cut-off gränser för MMSE bland de allra äldsta.

I studie I, II och IV undersöktes patienter med och utan kognitiva symtom på fyra vårdcentraler i Östergötland, Sverige.

I studie III inkluderades de som var födda år 1922 i Linköpings kommun. De personer som gav sitt samtycke genomförde som en del av ett större forskningsprojekt kognitiv testning med MMSE vid åldern 85, 86, 90 och 93 år. 
I resultaten från studie I ses att det kognitiva testet A Quick Test of Cognitive Speed (AQT) är möjligt att använda vid demensutredningar i primärvården. Testet är snabbt, enkelt och användarvänligt och hade i studien likvärdig sensitivitet som MMSE och kombinationen MMSE och Klocktest.

I studie II undersöks det förhållandevis korta och enkla multi-domän instrumentet Cognistat. Testet ger en möjlighet till en bredare uppfattning av patienters kognitiva nedsättning är enbart en övergripande total skattningssumma. Resultatet visar att Cognistat har en högre träffsäkerhet än kombinationen MMSE och Klocktest i demensdiagnostiken också i en primärvårdspopulation.

Resultaten från studie III bidrar med värdefull information avseende normativa värden och resultat på MMSE hos de allra äldsta. Den kognitiva funktionen även hos de som har en så ansenligt hög ålder som 85 - 93 år är väldigt god med medianresultat 28-29/30. Den undre 25:e percentilen låg på 26. Tidigare har i många länder ett pragmatiskt cut-off värde för misstänkt demensjukdom och behov av vidare utredning legat runt 24 poäng. Utifrån studiens resultat föreslår vi istället en cut-off på 26 poäng även hos de äldsta.

Studie IV undersöker ett lite mer omfattande kognitivt instrument Kognitiva Screeningbatteriet (KSB) och dess användning i demensutredningar i primärvård. Resultatet i studien visar en lite tveksam träffsäkerhet och detta satt i relation till att testningen är mer tids - och resurskrävande gör att vi inte rekommenderar ett breddinförande av KSB i basal demensutredning på vårdcentral i dagsläget.

Sammanfattningsvis så är objektiv kognitiv testning en viktig del av den basala demensutredningen i primärvården. Flera testar har i avhandlingsarbetet visat sig vara användbara vid demensdiagnostik på vårdcentral: MMSE, AQT och Cognistat. Införande av KSB är mer tveksamt i primärvården. De med hög ålder som är kognitivt friska presterar väldigt bra resultat på MMSE i den här studiepopulationen, vilket gör att vi föreslår en cut-off för kognitiv nedsättning även vid hög ålder till 26 poäng i en population med relativt hög utbildningsnivå. 


\section{LIST OF PAPERS}

I. Kvitting Anna S, Wimo Anders, Johansson Maria M, Marcusson Jan. A quick test of cognitive speed (AQT): usefulness in dementia evaluations in primary care. Scand J Prim Health Care. 2013 Mar;31(1):13-9. doi:0.3109/02813432.2012.751699.

II. Johansson MM, Kvitting AS, Wressle E, Marcusson J. Clinical utility of Cognistat in multiprofessional team evaluations of patients with cognitive impairment in Swedish primary care. Int $J \mathrm{Fa}$ mily Med. 2014;2014:649253. doi: 10.1155/2014/649253.

III. Kvitting AS, Fällman K, Wressle E, Marcusson J. Age-Normative MMSE Data for Older Persons Aged 85 to 93 in a Longitudinal Swedish Cohort. J Am Geriatr Soc. 2019 Mar;67(3):534-538. doi: 10.1111/jgs.15694.

IV. Kvitting AS, MD, Maria M Johansson OT, PhD, Jan Marcusson $\mathrm{MD}, \mathrm{PhD}$. Accuracy of the Cognitive Assessment Battery in a primary care population. Dementia and Geriatric Cognitive Disorders Extra. 2019;9:294-301. doi:10.1159/000501365. 


\section{ABBREVIATIONS}

AD Alzheimer's disease

VaD Vascular dementia

FTD Frontotemporal dementia

DLB Dementia with Lewy bodies

PDD Parkinson's disease with dementia

MCI Mild Cognitive Impairment

ECG Electrocardiogram

CT Computerised Tomography

ADL Activities of Daily Living

IADL Instrumental Activities of Daily Living

MMSE Mini Mental State Examination

CDT Clock Drawing Test

AQT A Quick Test of Cognitive Speed

$\mathrm{CAB} \quad$ Cognitive Assessment Battery

RUDAS Rowland Universal Dementia Assessment Scale

MoCA Montreal Cognitive Assessment

TMT A Trail Making Test A

TMT B Trail Making Test B

PPV Positive Predictive Value

NPV Negative Predictive Value

LR Likelihood Ratio

ROC Receiver Operating Characteristic

AUC Area Under Curve

$(J) \quad$ Youden index ((sensitivity + specificity)-1)

CUI+ ((sensitivity x PPV)-1)

GP General Practitioner

ELSA 85 Elderly in Linköping Screening Assessment

PHC Primary Health Care

DSMIV-V Diagnostic and Statistical Manual of Mental Disorders

ICD-10 The International Classification of diseases, 10th version 


\section{ACKNOWLEDGEMENTS}

"The young doctor should look about early for an avocation, a pastime,

that will take him away from patients, pills, and potions.......

No (person) is really happy or safe without one, and it makes precious little difference what the outside interest may be - botany, beetles or butterflies, roses, tulips, or irises, fishing, mountaineering or antiquities anything will do so long as he straddles a hobby and rides it hard."

William Osler. A way of life.

First and over all I would like to express my deepest gratitude and respect to all the patients and their relatives as well as employees who have contributed to this research. Without you, it would be nothing.

A number of unique individuals have made this thesis possible. Whether you are a part of the family, friends or professional colleagues, you have all played an important role in the outcome of this work.

Professor Jan Marcusson, my main supervisor. My deepest thanks for your constant encouragement, your support and for always believing in me, even when everyday life has been busy and challenging. Without your help, this would never have been accomplished. An even greater thank you for your contribution with important advice in the development as both a young doctor and lecturer, aside from the thesis. Maybe it has meant the most.

Thank you also to my co-supervisors, associate Professor Mats Foldevi and adjunct Professor Anders Wimo, for your support and for important insight into GPs' perspectives of dementia care, your knowledge of health economics and valuable comments on the thesis overall.

I would also like to thank:

Professor Lars-Olof Wahlund and associate Professor Staffan Nilsson for encouragement and important input at the half seminar;

Professor Carl Johan Östgren and all my friends at the Division of Community Medicine/General Practice, Linköping University for important lectures and discussions;

Assistant Professor Magnus Falk and Karin Rådholm for your friendly helpfulness no matter how simple the questions have been; and

Catharina Linderoth and Kajsa Bendtsen, Linköping University for great and important administrative assistance. 
Thank you to all my important research colleagues at the Department of Geriatrics in Linköping. Especially Maria Johansson for our cooperation with papers I, II and IV, and Elisabet Classon for important discussions throughout the work. I am looking forward to many years of research collaboration ahead.

Thanks also to all my dear colleagues and friends at the primary health care centre Ekholmen; Tina Holmberg for many invaluable phone calls and your hard work to get the schedule together; Ebba Curman and Lars Perers most of all for your constant support but also the courage to question important decisions and actions. Your guidance has been incredibly valuable in both the clinical professional practice and life.

To the head of the PHC Ekholmen Mahsa Pourheaidari and the former head of the PHC Ekholmen Michael Nilsson for always believing in the importance of research and for making this possible.

To Sanna Danell for the best and quickest IT support.

To my parents Eva Segernäs and Bengt Nordström for infinite love and countless occasions of practical support. My siblings Frida Segernäs and Johan Segernäs for making my life both easier and more fun.

To the worlds, best neighbours Family Sköller, who fixes pretty much everything.

To all my four-legged friends, especially Aero, who has kept me busy and filled my life with joy. Pernilla Svensson, your importance goes beyond words. Hard work requires fun and amazing breaks.

In memory of my beloved, grandfather Stig Segernäs for all his knowledge and inspiration over the years and my father-in-law Peder Martin Kvitting.

To the greatest love in life my three children Astrid, Vera, Vilgot and my husband John-Peder.

Finally, thank you to County Council of Östergötland, Medical Research Council of Southeast Sweden, the Alzheimer Foundation in Sweden and Swedish Brain Power who supported this research.

Linköping 2019-09-02

Anna 


\section{INTRODUCTION}

\section{Dementia in primary care}

Dementia is a clinical syndrome with progressive deterioration in cognitive and social function and the ability to live independently, due to progressive neurodegeneration. Dementia is an umbrella term referring to Neurocognitive Disorder (NCD) and DSM- 5 criteria divide this into major (dementia) and minor (Prodromal Disease or Mild Cognitive Disorder) NCD (6). Dementia most often affects older people, although young patients who receive the diagnosis early in life require special attention.

Cognition refers to thinking and related processes and according to DSM- 5 there are six cognitive domains that could be affected in both major and minor NCD:

- Complex attention (involving attention and information processing speed)

- Executive ability (planning, decision making, working memory)

- Learning and memory

- Language

- Perceptual - motor - visual perception/praxis

- Social cognition (recognition of emotions and behavioural regulation, social appropriateness)

According to DSM-5 dementia (major NCD) is defined by the following:

- There is evidence of substantial cognitive decline from a previous level of performance in one or more of the domains listed above, based on the concerns of the individual, a knowledgeable informant, or the clinician; and a decline in neurocognitive performance, typically involving test performance in the range of two or more standard deviations below appropriate norms

- The cognitive deficits are sufficient to interfere with independence and activities of daily living (ADL)

- The cognitive deficits are not in the context of delirium and not primarily attributable to another mental disorder

Dementia divides into three groups depending on the severity of the decline in cognitive and functional ability: mild, moderate and severe. 


\section{Risk factors for dementia}

Old age is the greatest risk factor for developing dementia (1). There is a non-modifiable link between Apolipoprotein E4 and dementia, and some rare dementia cases are connected to specific gene mutations $(<1 \%)$. An association between Downs syndrome and dementia is also recognised (7). Observational studies have identified several potentially modifiable risk factors for dementia, including hypertension, dyslipidaemia and obesity at midlife, diabetes mellitus, smoking, physical inactivity, depression and a low level of education (8).

Education is positively associated with cognition and studies are consistent with the cognitive reserve theory, suggesting that education reduces risk of rapid cognitive decline and progression to Alzheimer's disease (AD) (9). Results from healthy elderly people show that besides educational level, social-inclusion and engagement seem to have a protective effect on mental ageing, although this effect may not be effective in the oldest old (10).

\section{Prevention in primary care}

To date, there are no medical or pharmaceutical interventions to slow down the progression of dementia diseases, and therefore lifestyle intervention is a critical area for action. Appropriate management of cardiovascular risk factors and diabetes mellitus are essential in primary health care (PHC) and the role of the general practitioner is important regarding chronically ill patients in the Swedish health care system (11). The Global Burden of Diseases, Injuries, and Risk Factors Study 2016 (GBD 2016) reported metabolic condition as one of the major treatable risk factors worldwide in relation to attributable deaths, and attributable disability-adjusted life-years (DALYs) overall (12).

There is a great interest in different diets and their effects on cognitive function. Currently there is a lack of consensus among study findings whether adherence to a Mediterranean diet promotes benefits for age-related cognitive function (13). Epidemiological and observational studies have indicated that diets high in omega-3 polyunsaturated fatty acids might be beneficial for cognition in cognitively healthy older individuals (14). However, randomised interventions studies have shown negligible beneficial effects of omega-3 polyunsaturated fatty acids on cognition and mood $(14,15)$.

Physical activity has positive effects on atherosclerosis and metabolic risk factors (16). Some data indicate a positive effect on cognitive function 
but the results are not completely convincing (17). In a Swedish longitudinal study of females, midlife physical activity was independently associated with reduced risk of dementia disease later in life (18). Studies have also shown beneficial health effects of improved physical activity, energy expenditure, health-related quality of life, and hospitalisations for older primary care patients in general (19). Current international guidelines recommend at least 150 minutes of aerobic physical activity per week for achieving health protective effects. Physician -patient discussions concerning risk reduction via habitual aerobic physical activity offers a complementary intervention as part of broader dementia management in primary care (20).

\section{The Swedish registers}

The Nordic countries and Sweden in particular are world-renowned for their national population - and health registers. The main purpose is to identify all individuals and to aggregate data about the entire population. In Sweden, the history of national registration in parish registers goes back to the end of the $16^{\text {th }}$ century (21).

Six registers are held by the National Board of Health and Welfare in Sweden: "the national Cause and of Death Register", "the Medical Birth Register", "the National Cancer Register", "the National Patient Register (secondary care)", "the Swedish Prescribed Drug Register" and "the Dental Health Register”.

Other important registers for elderly patients in PHC are "PV-kvalitet", "Senior alert", "the Swedish register for palliative care" and "the Swedish BPSD register". BPSD refers to the behavioural and psychological symptoms in dementia. Severe BPSD are often associated with more advanced dementia. The aim of the BPSD register is to improve the quality of care of patients with dementia including reducing the symptoms of BPSD, reducing medication use in BPSD and providing national evidence-based standard care for these patients.

\section{SveDem}

The Swedish Dementia Registry (SveDem) started in 2007 with the aim of improving the quality of diagnostics, treatment and care of dementia patients in clinical practice (22). Newly diagnosed patients meeting the ICDcriteria for dementia are included in SveDem (23).

SveDem is a web-based registry with collected information about diagnostic workup, treatment, care and follow-up. In the Swedish system, both primary care physicians and specialists make diagnoses of dementia, and SveDem registers both. Younger patients, patients with a complex medical 
history, rapid decline in cognitive function and suspicion of a rare condition are possible reasons for referral to a memory clinic as well as patients in need of a second opinion and investigations that are more extensive.

The coverage is around $95 \%$ of all specialist memory clinics that diagnose dementia in Sweden but considerably lower for primary health care units (22).

\section{Demography}

Several studies and meta-analyses have tried to estimate the worldwide prevalence and incidence of dementia in the future. The statistical calculations are challenging due to problems with obtaining valid population data from the oldest age groups, especially in developing countries (24). An estimate of the dementia prevalence globally is crucial for public policy decisions and social planning (25).

The total number of older persons aged 60 years and above is expected to more than double globally between 2013 and 2050, reaching more than 2 billion in 2050 (26). The ageing population is likely to mean a large upcoming increase in the number of adults with dementia worldwide. More than 24 million people have dementia today, with an estimated one new case every 7 seconds (27). However, recent studies indicate a declining prevalence of dementia in the United States and other high-income countries (28). With the possibility of increase in educational level as one explanation, the full reason for the decline remains uncertain. Primary-care data from Spain reported a calculated age and sex standardised dementia incidence of 8.6/1000 person-years (29).

Previously a lower prevalence of dementia has been reported in developing countries compared to, for example, Europe. It is unknown whether this really reflects a genuine difference in disease incidence or rather can be linked to different age distributions in the study populations (30). Nevertheless, most people with dementia live in developing countries and the numbers are forecast to increase by more than $300 \%$ between 2001 and 2040 in India, China, and their south Asian and western Pacific neighbours (27)

\section{Demography in Sweden}

The demographic development in Sweden is no exception to that described globally. The predicted pattern is a mushroom - shaped population pyramid with few children and many elderly (Figure 1) (31). 


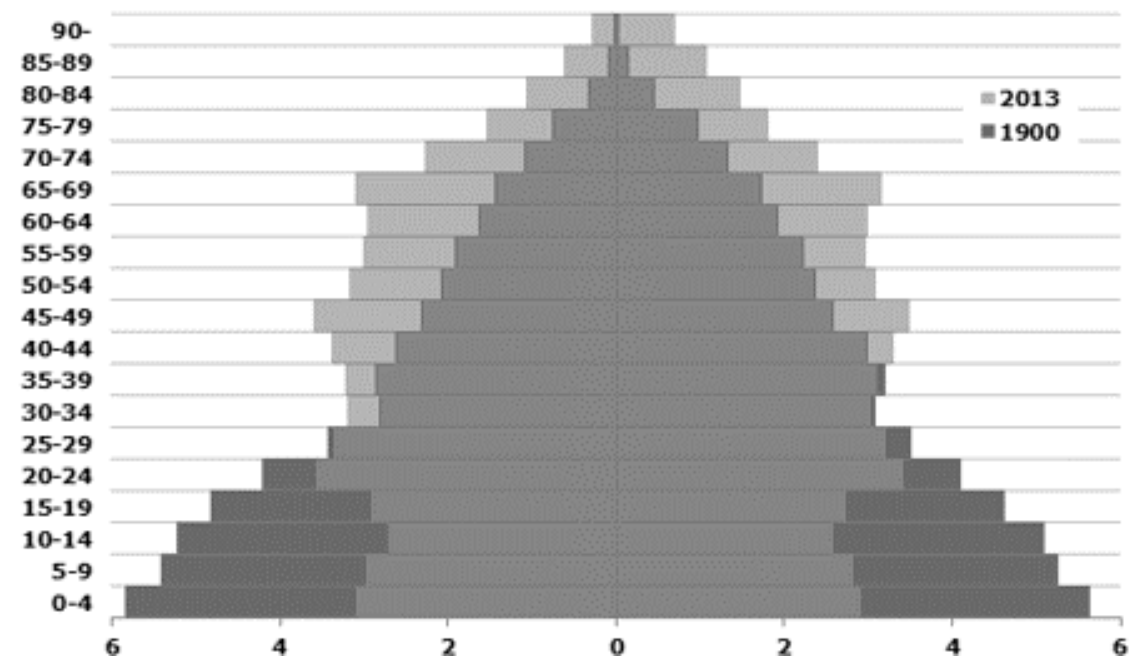

Figure 1. The Swedish population pyramid. Ages o to 100 years and parts of the entire population are shown in five year age groups for December 1900 (black) and December 2013 (light grey). Source: Statistics Sweden, Population statistics. http://www.scb.se/en, 2014.

\section{Social burden and economical cost}

According to the Global Burden of Disease estimates for the 2003 World Health Report, the disability burden for dementia was higher than for almost any other health condition, apart from terminal cancer and spinalcord injury (27). It is higher than both stroke and cardiovascular disease, even when taking into account that these types of calculations are possibly affected by different errors.

Direct cost in developed countries arise mainly from community and residential care but people with dementia are also high consumers of health care. Institutional costs make up about $60 \%$ of the total cost. The cost per person with dementia in Sweden has nevertheless dropped somewhat in recent years, mainly due to de-institutionalisation. Indirect costs link partly to the strain on family caregivers who shoulder a great responsibility $(27,32)$. However, worldwide costs of dementia are enormous and rising due to the increase in the total number of individuals with dementia (33). 


\section{Cognitive impairment}

Subjective and objective experience of cognitive impairment and dementia are common among patients in Swedish primary care (34). Cognitive impairment is an early symptom that might appear several years before a possible dementia diagnosis. The pathway from cognitive impairment to dementia is complex and several aspects of the disease progression is today unknown. In a PHC context it is important to note that the majority of people with mild cognitive impairment will not progress to dementia even after 10-years' follow-up (35).

Several other conditions aside from dementia can cause cognitive impairment, especially among elderly patients. Clinical differential diagnostic assessment is important to be able to detect or rule out other somatic and psychiatric disorders such as malnutrition, anaemia, cardiovascular diseases, diabetes, neurological diseases, alcohol overconsumption and abuse, depression and stress-disorders.

\section{Mild cognitive impairment (minor neurocognitive disorder)}

Individuals with mild cognitive impairment (MCI) often have subjective memory decline and show mild cognitive deficits on objective cognitive tests but activities of daily living are preserved (36).The objective cognitive impairment is not sufficiently severe to meet the criteria for dementia and there are consensus criteria for MCI diagnosis (37).

The MCI population has a ten-fold increased risk for of progression to dementia compared with the general population, of about 30-50\% within 5 years, making this group of great interest for early detection of dementia diseases $(38,39)$. The incidence of conversion to clinically probable Alzheimer's disease is at a rate of $10-15 \%$ per year. In contrast to other elderly patients who will develop Alzheimer's disease at a rate of $1-2 \%$ per year (36).

However, the group of elderly patients with MCI is heterogeneous. Follow-up data from elderly outpatients with manifest MCI described an overall rate of conversion 23.8 per 100 person-years. During the same followup period, $53.8 \%$ of participants remained stable and $17.3 \%$ reverted to normal (40). There is a high incidence of depression among MCI-patients and overlap between elderly patients with MCI, depressive disorder and dementia. In some patients, this symptom pattern might describe a possible clinical continuum rather than different disease pictures (41).

The discrimination between $\mathrm{MCI}$ and early $\mathrm{AD}$ from normal cognitive ageing is difficult but understanding the pattern and speed of decline is 
helpful. Cognitive ageing is generally characterized by a slow but steady decay in fluid cognition (42). Cognitive tests have shown to be usable tools for the possibility of predicting which individuals with MCI will progress to dementia. Predictive accuracy was highest when combining memory measures with a small set of other domains or when relying on broad cognitive batteries (43).

\section{Dementia (major neurocognitive disorder)}

The most common form of dementia is Alzheimer's disease (AD), which makes up approximately 50-60\% of all dementia diagnoses (1). The second most common is vascular dementia (VaD) $10-50 \%$, followed by mixed dementia and Dementia with Lewy bodies (DLB) $(44,45)$. More uncommon forms are frontotemporal dementia (FTD) and Parkinson's disease with dementia (PDD). However, accumulating data shows that mixed etiologies (comprising neurodegenerative and vascular features) account for a particularly high prevalence of mixed dementia in people older than 80 years, making mixed dementia perhaps the most frequent dementia diagnosis in elderly populations, also in primary care (8).

The distribution of dementia diagnoses in the SveDem registry from 2007 to 2013 (table 1) shows a considerably lower share of AD diagnoses in relation to the total and a relatively high proportion of mixed dementia (23). 


\begin{tabular}{|l|l|}
\hline & SveDem $(n=22,384)$ \\
\hline Alzheimer's disease (AD), early-onset & $740(3.3 \%)$ \\
\hline Alzheimer's disease (AD), late-onset & $7,396(33.0 \%)$ \\
\hline Vascular dementia (VaD) & $4,207(18.8 \%)$ \\
\hline Mixed dementia & $5,568(24.9 \%)$ \\
\hline Dementia with Lewy bodies (DLB) & $695(3.1 \%)$ \\
\hline Frontotemporal dementia (FTD) & $515(2.3 \%)$ \\
\hline Parkinson's disease dementia (PDD) & $426(1.9 \%)$ \\
\hline Unspecified dementia & $2,330(10.4)$ \\
\hline Others & $507(2.3)$ \\
\hline
\end{tabular}

Table 1. Dementia diagnoses from 2007 to 2013 in SveDem.

\section{The role of the general practitioner and primary care}

\section{Brief history of Swedish primary health care}

The history of Swedish general medicin goes all the way back to the 17th century. In the beginning of the 2oth century, Sweden had around 500 single-working doctors, often with their own private practice, in both the villages and cities. The work was described as hard and lonely, with difficulties recruiting new colleagues. In the middle of the 20th century, the idea of more complete medical centres grew and often 3-4 medical colleagues started to work together in a common medical centre. The first Swedish primary health care centre started in Dahlby, county of Skåne, 1968 and todays primary health care definition in Sweden originates from the year 1978 (46). 
In Sweden today, primary care practices comprise general practitioners (GPs) organised within multidisciplinary teams. Well-functioning PHC is characterised by high accessibility, coordination of care with a person-focus over time and continuity. Primary care is an important factor in the complex healthcare system, promoting outcomes like quality, efficiency and equity (47).

In a recent Swedish study, the result showed that active patient - doctor listing and more consultations in primary care are associated with reduced mean days hospitalised, when adjusting for socioeconomic status and multimorbidity level. In conclusion, the promotion of well performing primary care is worthwile to maintain good relationships with patients and possibly reduce mean days hospitalised (48). The risk of hospitalisation is increased in relation to morbidity burden and is therefore of particular interest in relation to elderly patients and individuals with cognitive impairment.

\section{The multiprofessional team in dementia care}

There are several studies indicating the importance of collaborative care and multiprofessional teams in the assessment and follow-up of patients with dementia in PHC (49). The main result and benefit is perhaps not improvement of the patient's cognition, but instead, other important aspects of care, such as improvements in behavioural and psychological symptoms of dementia and reducing caregivers stress (50).

Practice nurses in PHC and community nurses have an important role in the early recognition of patients with a risk of developing cognitive decline and dementia (51). The education for nurses in mental health is sometimes insufficient but it is very important to facilitate early recognition, since dementia often present in an atypical way without primary appearent memory loss. Data from a study looking into factors that facilitate helpseeking behaviours for cognitive impairment described the importance of family and friends, alongside well-informed health professionals (52).

Collaborative memory clinics in PHC are an example of multidisciplinary teamwork as a way of optimising dementia care $(53,54)$. One important facilitating aspect of building good and effective dementia assessments in primary care seems to be close collaboration between GPs and geriatric specialists (55). 


\section{GPs' role in dementia diagnostic procedures}

PHC often functions as a gateway to specialist services and secondary care, and for most people it is the primary route into the health care system. This and the ability to notice fluctuations in cognitive capacity over time means GPs often have a key role in the diagnosis of dementia. The majority of elderly people are in contact with a general practitioner, more or less regularly.

Despite this, several studies have highlighted the underdiagnoses of dementia in primary care facilities $(34,56)$. In an older patient population with multimorbidity the correlation between MMSE $\leq 23$ and a dementia diagnosis in medical records was low (57). In community care the number of individuals living with undiagnosed dementia is high (58).

There seem to be several contributing factors to the difficulties of a more active dementia diagnosis in PHC. One explanation is the belief among some GPs that they have little to offer patients diagnosed with dementia and for that reason sometimes do not reveal the diagnosis at all (59). Other described barriers include difficulties with communication about cognitive impairment, educational deficits, and challenges with system resources (60).

Objective test measurements have been shown to be more reliable than a patient's subjective memory complaints in dementia assessments (2). Subjective memory complaints lack specificity as they are often associated with depression (although there is an overlap between symptoms of depression between dementia disorders and affective disease). However, several studies indicate the lack of use of objective cognitive screening tools in dementia diagnosis in PHC (3). Some GPs do not perceive today's screening instruments as helpful in the diagnostic process and therefore do not use them $(4,5)$. There are also described problems in administering cognitive assessment instruments in PHC (61).

\section{Dementia assessments in primary care}

\section{Basic dementia investigations}

The diagnosis of dementia is clinical and patients with cognitive impairment in need of a basic diagnostic evaluation for dementia is common in PHC. The diagnosis is based on the history (from the patient and the caregiver), a physical examination and brief cognitive testing (62). Often some laboratory testing is necessary to rule out other underlying explanations for the cognitive impairment. Assessments of activities of daily living (ADL) is 
clinically valuable in the basic dementia investigation and can be performed using an objective ADL instrument evaluation (IADL) (63).

According to Swedish national guidelines, structural imaging with computed tomography is recommended with a high priority (or in selected cases magnetic resonance imaging) to find cerebrovascular pathology, atrophy and other treatable cerebral pathology (for example brain tumours) (64). Today, there is no recommendation for functional imaging, measurement of biomarkers and more extensive neuropsychologic testing in $\mathrm{PHC}$ diagnostical procedures (62).

\section{Cognitive tests in dementia assessments in primary care}

In this thesis, early cognitive screening is referred to as a first step of case findings of individuals with possible dementia disease in the clinical setting at the PHC. The research has not focused on epidemiological screening of asymptomatic individuals in the community. Today there is no convincing benefit of screening all elderly people with undetectable signs of the disease but early recognition of cognitive symptoms is crucial (65). Primary care studies and cognitive tests take place in an environment where there are patients with quite high suspicion (and risk) of having dementia and the text should be read in that context.

PHC cognitive tests for dementia assessments need both high sensitivity as well as quite high specificity. High sensitivity (low proportion of false negative test results) is important not to miss any dementia cases and high specificity (low proportion of false positive test results) is also important to avoid unethically wide investigations on cognitively healthy patients (66). If the GPs select the correct patients for investigations, there is an expecteded quite high prevalence of the disease in the clinical population and a high positive predictive value (ppv) would be desirable. However, the prevalence of positive dementia cases will never be as high in the primary care population as in a secondary specialist memory clinic setting.

\section{Brief overview}

To this date, no single dementia screening test has been shown to be accurate enough to be included alone in a guideline-level recommendation. Cognitive testing is an important part of a necessarily wide medical examination battery.

According to the requirements from the Swedish National Board of Health and Welfare the recommendation for basic cognitive testing in dementia diagnostic procedure in PHC is the combination of Mini Mental Sta- 
tus Examination (MMSE) and Clock Drawing Test (CDT), often complemented by another brief screening test for dementia or a multi-domain instrument $(64,67)$. MMSE mainly evaluates left hemisphere functions including attention, orientation, repetition, naming, recall and comprehension. CDT measures attentiveness, overall visual-spatial ability and construction but not episodic memory specifically (68).

As time pressure often is siginificant in PHC there are attempts to find a brief instrument that rapidly can detect cognitive decline. The General Practitioner Assessment of Cognition (GPCOG) takes approximately 4-6 minutes to administer. GPCOG is globally available in primary care settings but not so common in Swedish primary care. The test consists of one testing part and one interview part. GPCOG and MMSE seem to have similar accuracy for detecting dementia in PHC with slightly better sensitivity in GPCOG $(69,70)$. Data on the instrument are scarce.

There are several brief tests for subjective memory complaints but due to diagnostic uncertainty, they have limited clinical use. Another challenge is the inconsistency in the definitions used in the subjective memory tests and the many variations in the single questions and sets of questions (71). Examples of tests are the Subjective Memory Complaint (SMC) with a single question and Subjective Memory Complaint Clinical (SMCC) a seven question test (72). Another example is the Subjective Memory Rating Scale (SMRS) with a five-item scale (73). None of these is frequently used in Scandinavian primary care.

As objective memory complaints seem to be more reliable than subjective, it is important to get structured information from key-informants related to the patient. The Cognitive Impairment Questionnaire (CIMPQUEST) has been used in Sweden for many years; it has high reliability and validity and is therefore often recommended (74).

\section{Early diagnosis of dementia versus normal ageing}

One challenge is to discriminate between cognitive changes associated with normal ageing and signs of cognitive impairment indicating early dementia. The combination MMSE and CDT is helpful in finding dementia in moderate stages but not for detection of MCI and early diagnosis of dementia (68). Screening for MCI in primary care is questionable, as drugs for curative purposes are not currently available, but some of the cognitive tests developed for MCI diagnosis might be beneficial in PHC for early detection of dementia.

An example of a reasonably short cognitive tests focused on early diagnosis of MCI and dementia, is the MCI screen (MCIS) which measures executive function, working and episodic memory and language. The MCIS 
has shown an overall good accuracy in differentiating between normal ageing, MCI and mild dementia in a primary care population $(68,75)$.

There are several studies of the Montreal Cognitive Assessment Scale (MoCA) with promising results but data from PHC is scarce. Normative MoCA data are available from a large Swedish population cohort aged 65 to 85 years (76). The objective of MoCA was to develop a 10-minute cognitive test with the ability to assist first-line physicians in the detection of MCI (77). MoCA covers eight cognitive domains: short-term memory task with five nouns ( 5 points) and delayed recall after five minutes, visual-spatial with CDT (3 points) and cube copying (1 point), executive functions by adaptive tasks from TMT B (1 point), a phonemic fluency task (1 point), and a two-item verbal abstraction task (2 points); orientation to time and place (6 points) and finally attention, concentration, language and working memory. Maximum is 30 points. Several short versions of MoCA are available but to our knowledge has not been validated in Scandinavia or in PHC.

MoCA has been compared to another available short MCI test, the Qmci, in a study at an Australian outpatient geriatric clinic but has not been evaluated in PHC. The accuracy was eaqual for the tests but Qmci is shorter and easier for patients to complete (78).

In disease and drug trials, a new composite clinical outcome has been suggested, which is better designed and more sensitive for early stages of the disease and MCI. AD Composite Score (ADCOMS) consists of four Alzheimer's Disease Assessment Scale-cognitive subscale items, two MiniMental State Examination items and all six Clinical Dementia Rating-Sum of Boxes items (79).

\section{Tests of executive function and motor speed}

Data suggest reductions in perception and cognitive speed are an early sign of $\mathrm{AD}$, similar to reductions in delayed episodic memory and linguistic abilities (80). A Quick Test for Cognitive Speed (AQT) is in part one and two (colour and word) mainly regarded as a single-dimension speed test but the dual-dimension (part 3 colour-word) measures executive function in particular.

Besides AQT, there are several other available tests of executive functions and speed tests of motor function which may be used in PHC. Trail Making Test (TMT A) is a test in a more single-dimension fashion measuring attention and processing speed. TMT B consists of alternating numberletter sequencing and is considered an executive test (measuring cognitive flexibility) (81). The executive functions are complex visual-motor conceptual screening, planning, organisation, abstract thinking and response inhibition functions (82). TMT is regarded as a useful measure of executive 
dysfunction in elderly subjects and patients with MCI. The test requires intact visual and motor functions which somewhat restricts the use but an oral version of TMT B has been validated (83). AQT can be quickly implemented as a brief executive test in Swedish PHC and the use of TMT is less common. However, TMT is widely spread as an important part of more extensive neuro-psychological testing batteries in specialist memory clinics. In theory, nothing excludes the test from being useful also in investigations and early diagnosis in primary care.

Another possibility is the Stroop test which measures processing speed and an aspect of executive functioning involving response inhibition. The original version of the Stroop Test with 100 metric figures is extensive and not well adapted for elderly patients in PHC. However the test exists in many versions, most common is the Stroop Color and Word Test (SCWT) and the Victoria version $(84,85)$. Most applicable for primary care is probably the short Victoria version consisting of three sets, each set with 24 visual stimuli. The stimuli should be named within time and adjusted for age into T-scores; a table with normative values is available. Page 1 has words written in black ink. On page 2 the participants read forms in different colours and the colours are named. On the colour-and-word test on page 3 , none of the colour words match the colour of the ink in which they are printed. Participants name the ink colours.

Part three in the Victoria Stroop test measure an interference effect, which indicates the ability to inhibit prepotent responses, an executive function (86). The Stroop test and AQT share design features but the aspect of inhibition, linked to frontal brain function, is not a part of the AQT test. Functional imaging has shown different regional brain activation in the two tests. AQT mainly shows activation in parietal regions and low frontal activity, whereas Stroop showhs high activity in the frontal regions associated with the process of inhibition $(86,87)$.

\section{Dementia diagnosis in a multi-cultural population}

The majority of commonly used cognitive assessments tools have known cultural biases and the tests are limited when used in populations with diverse languages and low education. The Rowland Universal Dementia Assessment Scale (RUDAS) was developed in Australia especially for culturally and linguistically diverse populations. The RUDAS is a brief and freely available cognitive assessment tool. The correlation between RUDAS and MMSE in one comparative study was 0.77 (95\% CI 0.72-0.81) (88). 


\section{Differential diagnosis of dementia in primary care}

From theory and previous research there seem to be neuropsychological characteristics distinguishing $\mathrm{AD}$ from $\mathrm{VaD}$. In clinical practice, this is not always obvious, especially not early in the disease. There is more prominent memory loss and impaired retrieval from long-term storage in $\mathrm{AD}$ than in $\mathrm{VaD}$. Moreover, data suggest that $\mathrm{AD}$ and subcortical VaD affect perseverative behaviour in a different fashion, despite overall the same degree of cognitive decline. Executive functions often deteriorate early in VaD. With neuropsychological batteries designed to measure memory, language, praxis and executive functions, it was possible to distinguish between cognitive normal function, $\mathrm{AD}$ and $\mathrm{VaD}$ in a primary care population (89).

It is necessary for the GP to understand the different cognitive-behavioural profiles of neurodegenerative diseases to be able to place the cognitive test results in a clinical context, especially for early differential diagnostics in PHC. Patients with DLB often have mood-congruent visual hallucinations. Both patients with DLB and PDD have more prominent defective processing of visual information compared to patients with $\mathrm{AD}$ (90).

Considering this, moderate extensive tests are of interest that are not too time-consuming and which measure several cognitive domains, not only global cognitive function. Examples of available cognitive instruments in the category are Cognistat, Cognitive Assessment Battery (CAB) and CERAD-NP.

The Consortium to Establish a Registry for Alzheimer's Disease (CERAD-NP) is a brief neuropsychological assessment battery that measures the cognitive deficits typically accompanying Alzheimer disease (AD). The CERAD-NP, like the MMSE, comprises a semantic fluency task, a picture-naming task, a Word-List-Learning task with delayed recall and recognition, and a visual construction task (91). CERAD-NP is an example of a relatively brief multi-domain instrument and is widely used internationally; the test is available in PHC in Finland but uncommon in primary care centres in Sweden. A composite score for the CERAD-NP that could be used along with the normative data to provide an index of overall level of cognitive functioning has been suggested (92).

Some of the available cognitive tests for basic dementia assessments, used and relevant for Scandinavian PHC today are listed and compared in table 2. 
Table 2. List of some available cognitive tests for basic dementia assessments in PHC, used to varying extent in Scandinavian countries today.

\begin{tabular}{|c|c|c|c|c|c|c|c|}
\hline Test & Time & Sens & Spec & $\begin{array}{l}\text { Compari- } \\
\text { son with } \\
\text { the MMSE }\end{array}$ & $\begin{array}{l}\text { App- } \\
\text { lica- } \\
\text { bility }\end{array}$ & $\begin{array}{l}\text { Edu- } \\
\text { cation } \\
\text { bias }\end{array}$ & $\begin{array}{l}\text { Cul- } \\
\text { tural, } \\
\text { lan- } \\
\text { guage } \\
\text { bias }\end{array}$ \\
\hline \multicolumn{8}{|l|}{ Very short } \\
\hline CDT & $5 \mathrm{~min}$ & $\begin{array}{l}\text { Ade- } \\
\text { quate }\end{array}$ & Low & Worse & Easy & Some & Little \\
\hline AQT & $5 \mathrm{~min}$ & $\begin{array}{l}\text { Ade- } \\
\text { quate }\end{array}$ & $\begin{array}{l}\text { Ade- } \\
\text { quate }\end{array}$ & Equal & Easy & Little & Little \\
\hline GPCOG & $5 \mathrm{~min}$ & $\begin{array}{l}\text { Ade- } \\
\text { quate }\end{array}$ & $\begin{array}{l}\text { Ade- } \\
\text { quate }\end{array}$ & Equal & Easy & $?$ & $?$ \\
\hline \multicolumn{8}{|l|}{ Short } \\
\hline MMSE & $10 \mathrm{~min}$ & $\begin{array}{l}\text { Low- } \\
\text { Ade- } \\
\text { quate }\end{array}$ & $\begin{array}{l}\text { Ade- } \\
\text { quate }\end{array}$ & - & Easy & Some & Some \\
\hline MMSE+CDT & $15 \mathrm{~min}$ & $\begin{array}{l}\text { Ade- } \\
\text { quate }\end{array}$ & $\begin{array}{l}\text { Ade- } \\
\text { quate }\end{array}$ & Better & Easy & Some & Some \\
\hline MoCA & $15 \mathrm{~min}$ & High & $\begin{array}{l}\text { Ade- } \\
\text { quate }\end{array}$ & $?$ & Easy & Strong & Some \\
\hline RUDAS & $15 \mathrm{~min}$ & High & \begin{tabular}{|l|} 
Ade- \\
quate \\
\end{tabular} & $\begin{array}{l}\text { Equal-Bet- } \\
\text { ter }\end{array}$ & Easy & None & None \\
\hline \multicolumn{8}{|l|}{ Multi-domain } \\
\hline CERAD - NP & $20 \mathrm{~min}$ & High & $\begin{array}{l}\text { Ade- } \\
\text { quate }\end{array}$ & Better & $\begin{array}{l}\text { Diffi- } \\
\text { cult }\end{array}$ & Strong & Some \\
\hline Cognistat & $20 \mathrm{~min}$ & $\begin{array}{l}\text { Ade- } \\
\text { quate- } \\
\text { High }\end{array}$ & $\begin{array}{l}\text { Ade- } \\
\text { quate }\end{array}$ & Better & $\begin{array}{l}\text { Mode- } \\
\text { rate }\end{array}$ & Strong & Some \\
\hline CAB & $30 \mathrm{~min}$ & $\begin{array}{l}\text { Ade- } \\
\text { quate }\end{array}$ & $\begin{array}{l}\text { Ade- } \\
\text { quate }\end{array}$ & Equal & $\begin{array}{l}\text { Diffi- } \\
\text { cult }\end{array}$ & Strong & Some \\
\hline
\end{tabular}

? Indicates data unavailable or unpublished in PHC. Sens-Sensitivity, Spec-Specificity, MMSE Mini Mental State Examination, CDT - Clock Drawing Test, AQT - A Quick Test of Cognitive Speed, GPCOG - General Practitioner Assessment of Cognition, MoCA - Montreal Cognitive Assessment, $\mathrm{CAB}$ - Cognitive Assessment Battery, CERAD-NP - Consortium to Establish a Registry for Alzheimer's Disease Neuropsychological battery. 


\section{RATIONALE FOR THE THESIS}

With an ageing population worldwide, an increase in people with dementia is expected. The direct and indirect cost for dementia is substantial. Today there is no medical cure but with early diagnosis, there is a possibility for coping strategies to minimise symptoms for the patients and reduce strain on the family caregivers. PHC often functions as the primary way into the health care system. The majority of elderly people are in contact with a general practitioner, more or less regularly. This means GPs often have a key role in the diagnosis of dementia.

According to the Swedish National Board of Health and Welfare, cognitive tests are an important part of the basic dementia evaluation. However, there is a lack of use of objective cognitive screening tools in dementia diagnosis in PHC and an underdiagnosis of dementia. Some GPs do not perceive today's cognitive instruments as helpful in the diagnostic process and administration problems have been identified with cognitive assessment instruments in primary care.

The discrimination between $\mathrm{MCI}$ and early AD from normal cognitive ageing is difficult. The MCI population in PHC is furthermore very heterogeneous. The recommended combination MMSE and CDT is helpful in finding dementia in moderate stages but not for detection of MCI and early diagnosis of dementia.

For several of the cognitive tests used in the clinic today, primary care validation of the instrument is scarce and GPs need better normative values for the oldest old to improve the assessments. To improve the diagnostic process it is also necessary to look for new, brief multi-domain instruments with a potential for basic dementia investigations.

This thesis is an attempt to increase knowledge and improve the diagnostic evaluation of the cognitive instruments used for basic dementia evaluations in primary care.

Increased diagnostic accuracy provides an opportunity to improve medical and social care for patients with dementia and their relatives. 


\section{AIMS}

\section{General aim}

The aim of this thesis is to investigate the accuracy of several cognitive tests used in dementia assessments in PHC, especially among elderly patients: A Quick Test of Cognitive Speed (AQT), Cognistat and Cognitive Assessment Battery $(\mathrm{CAB})$ and present normative MMSE values for the oldest old.

\section{Specific aims}

- To validate the usefulness of AQT as a cognitive instrument in the diagnostic evaluation of dementia against final clinical diagnosis in primary care and to compare the AQT results with the MMSE and CDT.

- To investigate the diagnostic accuracy and clinical utility of the brief multi-domain instrument Cognistat for identifying individuals with cognitive impairment in a primary care population.

- To present normative MMSE values from an elderly Swedish cohort aged 85-93 years, and to analyse, and compare data from a brain healthy subgroup of the same age.

- To evaluate the accuracy of the CAB test in a primary care population based on routine clinical cases in dementia investigations in PHC. 


\section{MATERIAL AND METHODS}

\section{Study populations}

The studies in this PhD thesis originated from data of participants in two different populations. One was a primary care population (studies I, II and IV) and one was a population-based survey (study III) where all residents were born in 1922 and living in the municipality of Linköping, Sweden.

\section{Primary-care population}

Studies I, II and IV systematically recruited participants from four PHC centres between 2007 and 2009. The four primary care centres served a total population of 49800 people; 11200 were 65 years or older.

The inclusion criteria were as follows: age 65 years and above, with complaint or suspicion of cognitive impairment due to possible dementia disease by the patient, an informant or employees in PHC. Inclusion of the study participants and written informed consent was collected at the appointment with the GP. Altogether 52 individuals met the inclusion criteria. These patients followed a study protocol according to standard dementia basic evaluations in PHC, county council Östergötland and according to Swedish national guidelines for dementia investigations and care, including lab tests and CT scan (64).

Twenty-nine individuals who were presumed to be cognitively healthy and visiting primary care for some other medical problem during the same period were also included to extend the study group. These 29 patients completed a short questionnaire regarding self-estimated memory and identified themselves as cognitively well-functioning; the general practitioner agreed with their self-assessment.

Exclusion criteria for all participants were a medical history or record with a known dementia diagnosis, ongoing verified severe or unstable psychiatric disorder, brain tumour or brain-related infection and recent stroke or head trauma. Patients with a previous psychiatric diagnosis but in a clinically stable condition (determined by the general practitioner) and with unmodified antidepressant medication for the last 6 months were included.

All 81 patients performed the cognitive tests MMSE, CDT, AQT and Cognistat during the same appointment with an occupational therapist in primary care. The patients then visited a university memory clinic for more 
extensive testing in a standardised order by a trained nurse and a neuropsychologist, and had an evaluation by a geriatric specialist. The final clinical diagnoses were based on the investigation results and consensus conclusions provided by the neuropsychologist and a geriatric specialist.

The DSM IV criteria were the basis for the dementia diagnosis, which was clinically journaled according to ICD10 (93). The dementia differential diagnosis followed research criteria for each dementia diagnosis $(44,45$, 94-96). MCI diagnosis was assessed according to the criteria from the key symposium (37).

\section{ELSA 85}

In study III we analysed data from the ELSA 85, a population-based survey. All individuals born in 1922 in Linköping, Sweden, were identified through the local authorities' register and invited to be a part of the study by post. See figure 2 for flow-chart over the ELSA 85 cohort.

\section{Baseline data}

Baseline data registration took place between 2007 and 2009. Then 496 (76\%) out of the 650 individuals first identified provided written informed consent and answered a postal questionnaire. Finally, 380 out of those who filled in the questionnaire were willing to participate in the first phase of the study, which was a home visit by an occupational therapist. Baseline data about the participants' ADL abilities and a cognitive assessment by MMSE was collected at the home visit. The study individuals then had a visit at the geriatric clinic for further cognitive testing, blood samples, electrocardiogram (ECG) and physical examination by a doctor. In total, 374 individuals had a complete baseline registration at age 85 years (T1).

The postal questionnaire had questions about medical history and current prescribed drugs. It also included the European Quality of Life 5 Dimensions questionnaire (EQ-5D). Medical history was also obtained systematically from medical records and the medical examinations.

\section{Follow-up data}

Follow-up stages were completed after 1 year at age 86 years (T2), 5 years at age 90 (T3), and 8 years at age $93\left(\mathrm{~T}_{4}\right)$. T1 and $\mathrm{T} 2$ consisted of three phases: a postal questionnaire, a home visit by an occupational therapist, and a visit to the memory clinic in Linköping. The protocol at $\mathrm{T}_{3}$ and $\mathrm{T}_{4}$ was shortened to include only a home visit, during which the MMSE and 
self-report questionnaires were administered. A trained nurse or occupational therapist performed the MMSE examination in the home of the patient in most cases.

\section{Brain-healthy group}

For analysis of the brain-healthy group at age 93 years $(n=38)$, people with known diseases that can cause cognitive decline were excluded. The conditions concerned were neurological (e.g., stroke, epilepsy, multiple sclerosis, normal pressure hydrocephalus, Parkinson's disease), cognitive (e.g., dementia, objective mild cognitive impairment), somatic (e.g., chronic obstructive pulmonary disease with hypoxia, insulin-dependent diabetes, metastasised cancer), and psychiatric disease (e.g., psychosis, depression), severe head trauma, and drug abuse.

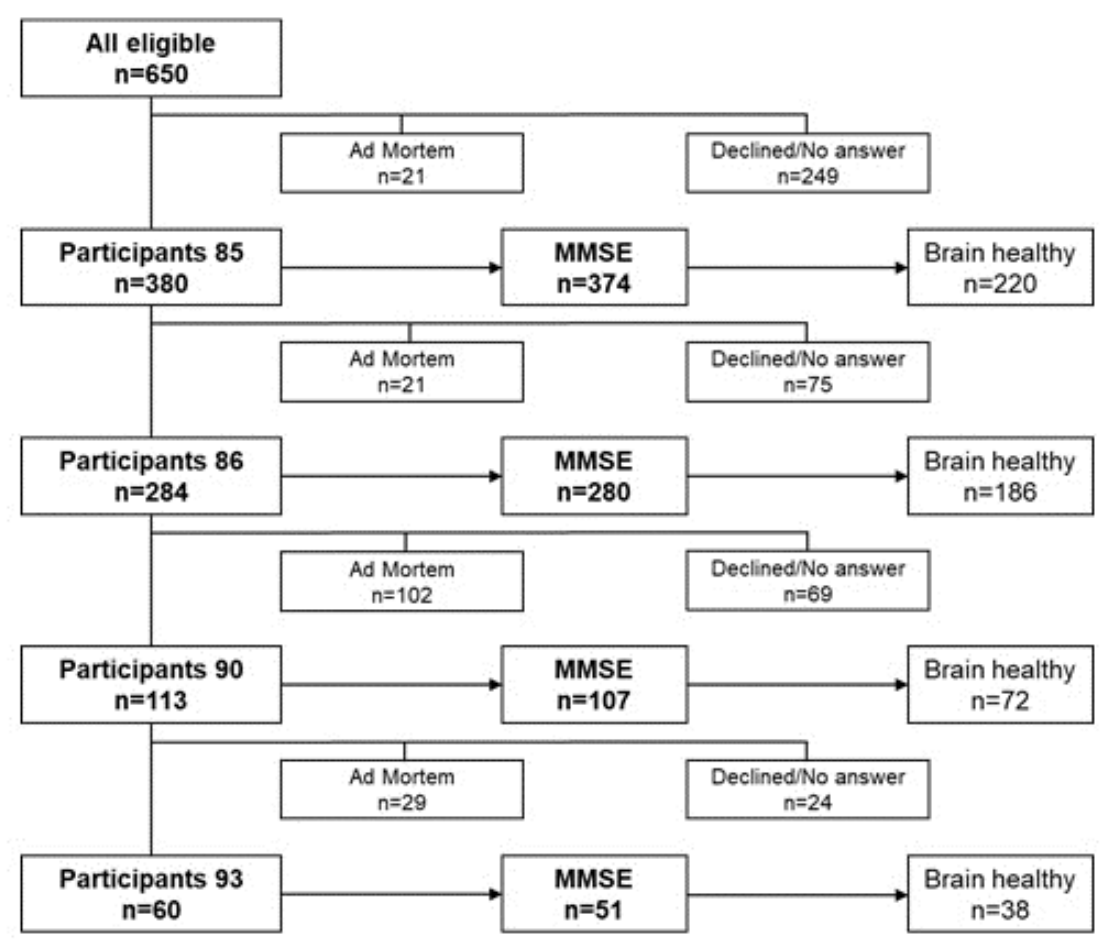

Figure 2. Flow-chart over the ELSA 85 cohort. 


\section{Measures}

\section{Cognitive tests}

The purpose of this section is to give a short general description of the cognitive tests used methodologically in the thesis. Please see the introduction section for a more comprehensive background of the cognitive tests available for dementia diagnosis in PHC.

\section{Mini Mental State Examination}

MMSE is the most widely used and studied short cognitive instrument and the test is available worldwide, free of charge. The instrument measures global cognitive function, including orientation, attention, memory, language, and visual construction through 12 items (97). MMSE takes around 10 minutes to administer. Maximum score is 30 points, with lower scores indicating more impaired cognition. The test was used in all studies I, II, III and IV but with slight differences in analyses of the cut-off values based on the issues.

In study I results on MMSE $\leq 26 / 30$ was regarded as cognitive impairment in the statistical analyses.

In study II the cut-offs were $\geq 27 / 30$ = no cognitive impairment; 21-26 = mild cognitive impairment; 11-20 = severe cognitive impairment (98). The cut-off $\geq 23 / 30$ for no cognitive impairment was used for comparative data analysis.

In study III normative MMSE values are presented as percentiles for each age group and separately for the brain healthy group.

In study IV, the same cut-off as in study $\mathbf{I}, \mathrm{MMSE} \leq 26 / 30$, was regarded as cognitive impairment.

\section{Clock Drawing Test}

The CDT measures impairment in mainly visuo-construction and executive functions but also memory (mostly semantic memory) $(99,100)$. Difficulties in clock-drawing and associations with decline, especially in parietal brain regions, have been shown in $\mathrm{AD}$ patients (101). The CDT is a short test with an administration time of less than 5 minutes. There are a numerous different scoring systems and ways to administer the CDT test (102).

In studies I, II and IV scoring according to Shulman was used with a 1 - to 5 - point scale starting with a blank sheet of paper (103). Five points 
correlated to a perfectly drawn clock and o points to a not - at - all representative clock picture. Small visuospatial errors resulted in 4 points, and if the clock indicators were misplaced but the numbers correctly placed they would score 3 points and 1 to 2 points depending on the severity of the misorganisation of the numbers on the clock. Every value below 5 points was considered as an indicator of cognitive impairment.

\section{Cognistat}

The test was initially named the Neurobehavioural Status Examination and the instrument is primarily developed and validated to detect cognitive deficits among patients with neurological conditions for example post neurosurgery and stroke (104).

The neurobehavioral cognitive status examination (Cognistat) has 10 subtests that assess multiple cognitive domains such as orientation, attention, language, constructive ability, episodic memory, calculation, and reasoning (similarities and judgement). The language subtest consists of three parts comprising comprehension, repetition and naming (105). It has been shown that the MCI group performed significantly worse than the cognitively healthy group on subtests in Cognistat. Besides episodic memory, several other cognitive domains, such as constructive ability and abstract thinking, were also impaired (106). However, the decline in episodic memory was the most prominent.

The test is brief, and a cognitively healthy individuals needs around 510 minutes to finish it, and individuals with cognitive impairment around 15-20 minutes.

A low value in a separate test indicates cognitive decline in that domain. Each subtest starts with a screening test (except memory and orientation); if the patient fails the screening item, the test continues with a metric section. The result is shown in a graphic way as a cognitive status profile and not as an aggregation of total global function. The graphic profile adds a qualitative aspect to the test result beyond the numeric sum. In study II we used the Swedish manual for administration of the test accoring to instructions with available age-normative values (107).

\section{A Quick Test of Cognitive Speed}

AQT is a short test, easy to administer and has therefore quickly spread in primary care dementia diagnosis, especially in Sweden. The test takes around 3-5 minutes in cognitively healthy adults and around 5 minutes if the individual has some cognitive impairment. AQT is supposed to measure 
general cognitive and perceptual speed including reaction, retrieval, and response time as well as working memory and time for making decisions and cognitive set shifting $(87,108)$.

The test is not affected by gender and only weakly with education (109). AQT has been shown to be affected by age to a small extent in normative studies, with longer time correlated with older age (110, 111). In one study linear regression indicated a prolonged speed processing time with 2 to 4 seconds (depending on the task) per decade (112). This is concordant with the Salthouse reported age theory which proposes some age - correlated changes in visual-pattern comparison speed, fluid intelligence, and working memory (42). However, a recent study in patients with MCI and early $\mathrm{AD}$ showed no age effect in this population, suggesting that the brain disease has more influence on the recorded test time than age (113).

AQT is performed by reading a set of colours, forms, and colour-form combinations as fast as possible (Pearson education, USA). The test consists of three parts where the patient rapidly names (1) the colour of 40 blue, red, yellow, or black squares (AQT colour), (2) the form of 40 black shapes (circles, squares, triangles, or rectangles; AQT form), (3) the colour and shape of 40 figures (consisting of previous colours and forms; AQT colour-form) (114).

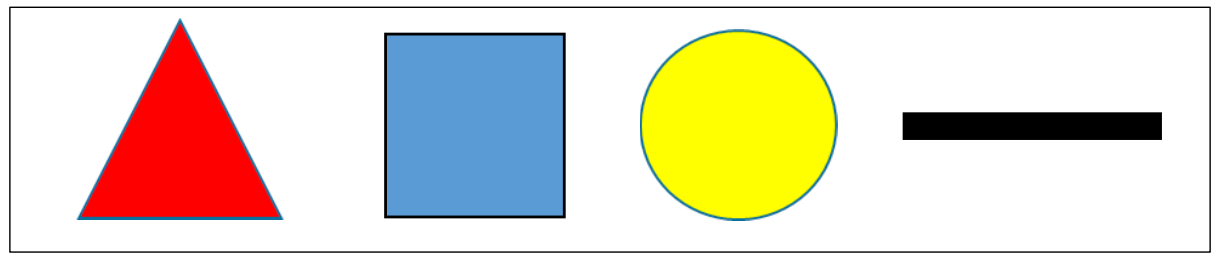

Figure 3. Illustration of the coloured geometric figures in AQT.

According to test instructions, the patient is allowed to use other names to describe the colours and shapes as long as the naming is consistent throughout the test. The time in seconds is recorded for each of the three tasks (single-dimension (1), single-dimension (2) and dual-dimension (3)). Previous studies have shown a low number of naming errors, the seconds required for self-correction, and switch cost is reflected in the total time for each plate in the test (115).

In study $\mathbf{I}$ an occupational therapist administered the AQT and the patient completed all three tasks. In the data analysis, calculations were done using the dual-dimension time (task 3 ) with the cut-off $>70$ seconds distinguishing those with a response time indicating cognitive impairment from 
no cognitive impairment, in comparison with the clinical consensus diagnosis of the dementia investigation in PHC. The dual-dimension was choosen since it has been shown to be the most sensitive predictor for prolonged test-times (116).

\section{Cognitive assessment battery}

$\mathrm{CAB}$ is a composition of severel different previously used and separately validated cognitive tests. $\mathrm{CAB}$ comprise the domains speed and attention (Symbol Digit Modalities Test), learning and episodic memory (immediate and delayed text recall), visuospatial functions (Clox and drawing and copying a cube), language (short version of Token Test and naming 30 items from the Boston naming test) and executive functions (short version Victoria Stroop). The different tests are presented in a standardised order and overall $\mathrm{CAB}$ takes around 20-30 minutes to perform with instructions (117).

Every test in $\mathrm{CAB}$ has a table with normative values (means and standard deviations for various ages). On each test, the result obtained is a grading of the cognitive function as above the mean, at the mean or below the mean. In this way, it is theoretically possible to get a quick overview of the patient's cognitive profile. From previous studies, it seems CAB could possibly distinguish between cognitively healthy controls, MCI, dementia, and perhaps subgroup vascular from non-vascular MCI $(117,118)$. CAB was originally designed to be able to detect minor decline in cognitive capacity compared to MMSE most frequently used in PHC.

In study IV CAB was administered at a memory clinic by a trained nurse or an occupational therapist according to the Swedish manual (117). Concordant with Nordlund et al we also used >2 standard deviations from the mean for "no cognitive impairment" as the cut-off to define cognitive decline.

\section{Postal questionnaire}

The postal questionnaire in study III (ELSA 85) charted aspects of socioeconomic status, occupation, education, social network and use of assistive technology. The study participants responded to the written questions on their own.

\section{EQ-5D}

In study III health related quality of life was measured by EQ-5D that was attached to the postal questionnaire. EQ-5D is commonly used in research 
as a health quality measurement and the instrument is validated in general populations, elderly people and among individuals with possible cognitive impairment $(119,120)$. Aspects of pain/discomfort, anxiety/depression, mobility, usual activities and self-care are in the assessment.

\section{Statistical analysis}

In studies I and II data were collected and calculated in the statistical program SPSS for Windows 19:0 (SAS Institute, Cary, NC, USA). In the descriptive analyses we used chi-square for gender, comorbidity, and medication; independent t-test was used for age, education, and the test variables. Sensitivity, specificity and predictive values were calculated in both studies and likelihood ratios (LR) were presented in study $\mathbf{I}$.

In study I analyses were made for the tests alone and in combination. When combining different tests, one positive result in any of the test was enough to register the combination as positive for cognitive impairment. The area under the receiver operating characteristic (ROC) curve (AUC) was used to quantify the binary outcomes ("no cognitive impairment" and "cognitive impairment"). AUC between 0.7 and 0.9 was considered to be good accuracy for the cognitive tests (121).

Correlation data were analysed parametrically with Pearson's correlation and non-parametrically with Spearman's rank correlation.

In study II age, education, duration of symptoms and test results were analysed with the parametric student $t$ test. P-value $<0.05$ was regarded as statistically significant.

AUC was also calculated for the different subtest domains in Cognistat. Besides sensitivity, specificity and predictive values additional analyses were done with the Youden index $(\mathrm{J})$ and the CUI+ $(122,123)$.

In studies III and IV analysis of the data was done in the statistical program SPSS for Windows version 24:0 (SAS Institute, Cary, NC, USA).

In study III the MMSE scores originate from the same population on four separate occasions between ages 85 and 93 years. MMSE normative data at ages $85,86,90$, and 93 years are presented by mean, median, range and percentiles. The Mann-Whitney $U$ test was used in the analyses of the differences in MMSE between males and females, and between the total group and the brain-healthy group.

We also separately analysed MMSE versus age for the same individuals $(n=50)$ who reached 93 years of age and delivered data at all four time points by mixed-models analyses and pairwise post hoc comparisons. The mixed-models analyses used a diagonal repeated covariance structure for 
the data and is advantageous when multiple correlated measurements are performed.

In Study IV the non-parametric Mann-Whitney U test was used for group comparisons between "no cognitive impairment" and "cognitive impairment" since the demographic data were not not homogenous and not normally distributed between the groups. Differences between groups for the cognitive tests were analysed using a univariate analysis of variance where the model was corrected for age and education and presented as median (range) values.

For discrimination between "no cognitive impairment" and "cognitive impairment" assessments with C-statistics and ROC were done to quantify the binary outcomes with AUC calculations.

Concordant with Nordlund et al we used $>2$ standard deviations ( $>2$ $\mathrm{SD}$ ) from the mean for "no cognitive impairment" as the cut-off to define cognitive decline for the $\mathrm{CAB}$ (117).

\section{Ethical considerations}

All research studies that underlie the results in this thesis, including permission to obtain data from all registers held by the County Council of Östergötland, comply with the ethical rules stated in the Declaration of Helsinki. Ethical approval was obtained from the Regional Ethical Review Board at Linköping University, Sweden. Studies I, II and IV (dnr 2007/137-07) and the ELSA 85 study III (dnr 2006: 141-06; 2012: 332-31; 2014: 455-31).

The patients studied in the primary care population underwent their examinations and testing mainly as a part of the clinical investigation. However, they had to perform several extra cognitive tests and to limit possible bias from fatigue; they performed the extended neuropsychological tests during another appointment at the memory clinic. Physical examination was carried out with respect for the individual's integrity. There was no substantial delay in time until the final diagnosis due to the study.

The cognitively healthy individuals in the primary care study did not undergo a computer tomography examination or any blood samples.

All data were unidentified, aggregated and presented at a group level. Overall, the risks are assessed as low and the benefits from the results estimated outweigh the risks associated with the studies. 


\section{RESULTS}

\section{Paper 1}

Early detection of dementia in PHC is difficult and adequate diagnostic instruments are important $(61,124)$. MMSE is the most widely used diagnostic test but the test results are influenced by age, education and ethnicity, and the accuracy has been questioned $(125,126)$. The brief test AQT is affected minimally by age and not at all by gender or education (111). AQT is relevant for PHC dementia diagnostic assessment, and so far, PHC data is scarce.

The aim of the study was to validate AQT as a cognitive instrument in the diagnostic evaluation of dementia against final clinical diagnosis and to compare the AQT results with the MMSE and CDT in primary care.

\section{Results}

Results were calculated for 79 patients. Thirty-three patients were diagnosed with no objective cognitive impairment and 46 patients with cognitive impairment. Among the patients with cognitive impairment the distribution of diagnosis was as follows: MCI 16 (35\%), AD 12 (26\%), mixed dementia six (13\%), VaD five (11\%), LBD one (2\%), PDD one (2\%), dementia of uncertain origin two (4\%), and three patients (7\%) had comorbidity with depressive disorder.

The sensitivity, specificity, PPV and NPV for the individual tests and combinations of tests are presented in table 3 .

Table 3. Sensitivity, specificity, PPV and NPV for the cognitive tests

\begin{tabular}{ccccc}
\hline Cognitive test & Sensitivity & Specificity & PPV & NPV \\
\hline MMSE & 0.587 & 0.909 & 0.900 & 0.612 \\
CDT & 0.261 & 0.879 & 0.750 & 0.460 \\
AQT & 0.783 & 0.667 & 0.766 & 0.688 \\
MMSE+CDT & 0.696 & 0.788 & - & - \\
MMSE+AQT & 0.913 & 0.636 & - & - \\
AQT+CDT & 0.783 & 0.576 & - & - \\
MMSE+CDT+AQT & 0.913 & 0.545 & - & - \\
& & & & \\
\hline
\end{tabular}


The positive likelihood ratios were as follows: MMSE: 6.45; AQT: 2.35; and CDT: 2.15. The negative likelihood ratios were as follows: MMSE: 0.45; AQT: 0.33; and CDT: 0.84 .

ROC curve analysis of AQT at cut-off 70 seconds showed an AUC of 0.773 , for MMSE of 0.849, and for CDT of 0.574 (Figure 3).

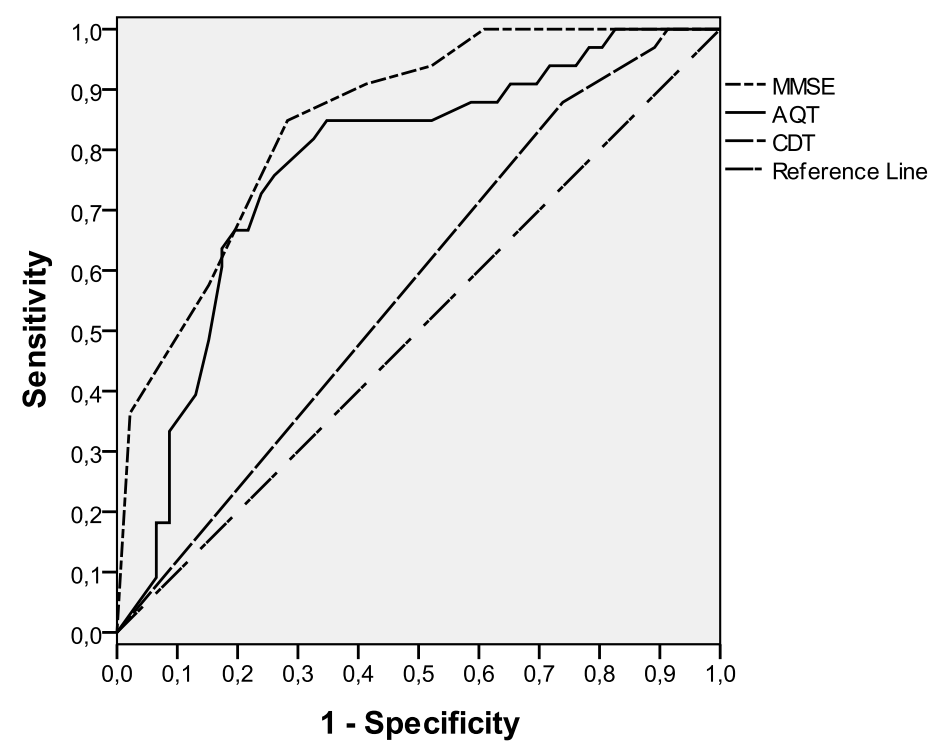

Figure 3. Receiver operating characteristic (ROC) curve. Null hypothesis: true area $=0.5$. Area under curve $(\mathrm{AUC}): \mathrm{AQT}=0.773 ; \mathrm{MMSE}=0.849$; and $\mathrm{CDT}=0.574$.

\section{Comments}

The results in this study show that AQT is a usable test for dementia diagnosis in PHC. Sensitivity for AQT is superior to CDT, equivalent to MMSE, and comparable to the combination MMSE and CDT. The sensitivity and specificity of MMSE in combination with CDT is 0.696 and 0.788. A possible new combination with MMSE and AQT for diagnosis of dementia in PHC shows promising results with sensitivity 0.913 and specificity 0.636 .

Combining the three tests together did not provide a convincing improvement on the results.

The AUC 0.773 for AQT was above the recommended level of 0.7 which was concidered to be good enough for diagnostic tests. 


\section{Paper 2}

Cognitive decline and early dementia may present with symptoms other than memory loss and DSM-IV requires memory and another cognitive domain to be impaired for a dementia diagnosis (127). Therefore, a combination of a memory test with an instrument testing other cognitive domains is of great interest for dementia diagnosis in PHC. Combined memory and executive function tests can probably to a higher extent identify mild cognitive impairment and patients with MCI with risk of progression to dementia (128).

Cognistat is an interesting dementia diagnostic instrument for use in primary care as it includes several cognitive subtests and is easily administered (105).

The aim of this study was to investigate the diagnostic accuracy and clinical utility of Cognistat for identifying individuals with cognitive impairment in a primary care population. In addition, this study investigated the diagnostic accuracy of Cognistat compared with MMSE and CDT which are currently used in the PHC dementia diagnostic assessments.

\section{Results}

The final data were analysed on 46 individuals with cognitive impairment and 33 individuals with no cognitive impairment. The cognitively impaired group had a significantly higher mean age and lower education level than the group with no cognitive impairment.

The test results were significantly lower in the group with cognitive impairment (Table 4). 
Table 4. Descriptive data and test results (mean, $\mathrm{SD}=$ standard deviation) for the groups No cognitive impairment and Cognitive impairment.

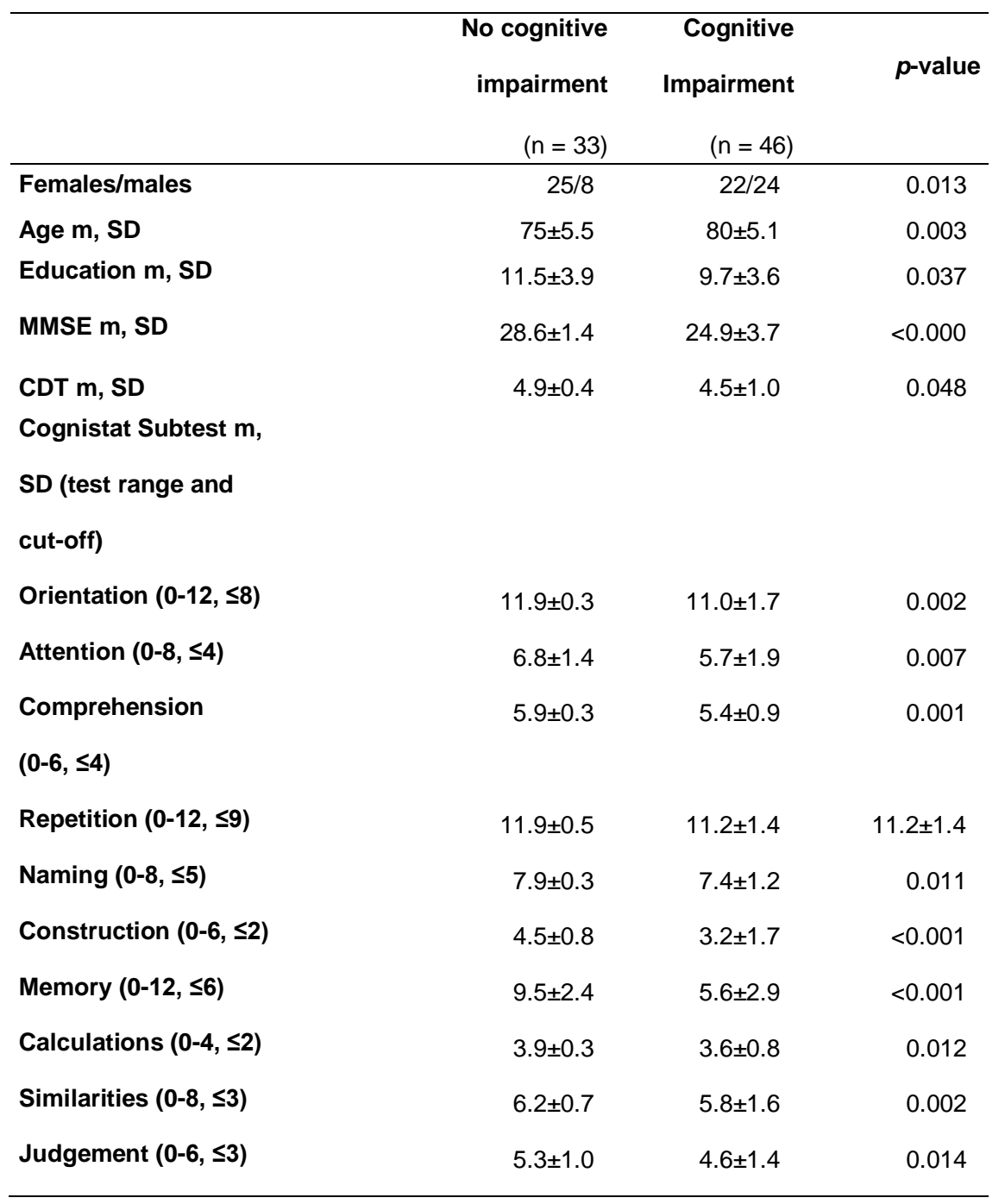

P-value analysed by Chi-square for gender, independent student's t-test for age, education and the test variables MMSE, CDT, and Cognistat. Significant p-value <0.05.

Analysis of one reduced domain alternatively two reduced domains on Cognistat showed sensitivity 0.85 and specificity 0.79 as well as sensitivity 0.57 and specificity 0.97. PPV and NPV were 0.85 and 0.79 as well as 0.96 and 0.62 with one respectively two domains impaired. CDT had a low sensitivity 0.26 and a high specificity 0.88 . Cognistat was superior in sensitivity 
and specificity even when comparing to the combination of MMSE and CDT (with cut-off MMSE $\leq 26$ as well as $\leq 23$ ).

Cognistat $\geq 1$ subtest had the best CUI+ of 0.72 corresponding to good whereas MMSE $\leq 26$ had CUI+ 0.53 (satisfactory). MMSE $\leq 23$ only had CUI+ 0.26 (poor) as well as CDT 0.20.

Analysis with ROC-curve and AUC for each subtest of Cognistat showed impairment in memory and construction as the most prominent impairments.

Table 5. Diagnostic accuracy of the tests validated against final clinical diagnosis (Cognitive impairment $n=46$ versus No cognitive impairment $n=33$ ).

\begin{tabular}{lllllll}
\hline Test & Sens & Spec & PPV & NPV & LR+ & LR- \\
Cognistat & 85 & 79 & 85 & 79 & 4.05 & 0.19 \\
MMSE & 59 & 91 & 90 & 61 & 6.45 & 0.45 \\
CDT & 26 & 88 & 75 & 46 & 2.15 & 0.84 \\
MMSE+CDT & 70 & 79 & 82 & 65 & 3.28 & 0.38 \\
\hline
\end{tabular}

Sens-Sensitivity, Spec-Specificity, PPV- Positive Predictive Value, NPV-Negative Predictive Value, LR+-Positive Likelihood Ratio, LR-Negative Likelihood Ratio, MMSE-Mini Mental State Examination, CDT-Clock Drawing Test. Results on Cognistat analysed with one reduced domain.

\section{Comments}

The results of this study indicate that Cognistat is appropriate for dementia diagnosis in PHC. The relatively high sensitivity and PPV in combination with a rather good specificity and NPV makes the test relevant for PHC dementia investigations. More important, our results also show that today's recommended combination of MMSE and CDT is not ideal for dementia investigations in PHC.

Overall, the results for Cognistat in this study are superior to those for MMSE and CDT, also in combination. It is promising for improved dementia diagnosis in PHC with a quick and easily administered multi-domain test for dementia assessment. The results are also helpful in providing better information if the patient needs to be referred to a specialist memory clinic for further investigations. 


\section{Paper 3}

The majority of patients with dementia receive their diagnosis when they are older. According to several guidelines MMSE plus CDT is the recommended combination for basic dementia investigations, despite numerous limitations $(126,129,130)$. There is no absolute MMSE value discriminating between cognitively healthy and cognitive impairment. To be able to ensure a dementia diagnosis additional information in the investigation process is necessary in combination with cognitive test results (131).

However, normative MMSE data and cut-offs for cognitive impairment in elderly populations are helpful in the dementia diagnosis process in PHC. In many countries, MMSE 24 is used as a cut-off value for pathology (132). In a lower-educated populations a cut-off of 21 has been suggested (125). Data from previous age cohorts are scattered and seem to be improving in MMSE results when comparing different age cohorts over time (133). Current data from highly educated populations are scarce.

The aim of this study was to present normative MMSE values from an elderly Swedish cohort aged 85-93 years. We also analysed and compared data from a brain healthy subgroup of the same age.

\section{Results}

Residents $(n=650)$ born in 1922 and living in the municipality of Linköping were invited to participate during 2007, ELSA 85. In total, 374 individuals were tested with MMSE at age 85 (T1), 280 at age 86 (T2), 107 at age 90 (T3) and 51 at age $93\left(\mathrm{~T}_{4}\right)$. For the brain healthy subgroup individuals with known diseases that can cause cognitive decline (from medical records and medical history) were excluded. These data were analysed separately. The number of brain healthy individuals were as follows: $\mathrm{T} 1 \mathrm{n}=$ 220), T2 $(n=186), T_{3}(n=72)$ and $T_{4}(n=38)$. Data from the selected individuals $(n=50)$ who reached 93 years of age $(n=50)$ were looked at specifically to analyse MMSE results versus age.

Median MMSE values for the total population over the ages 85, 86, 90, and 93 years was 28 for all ages investigated. The $25^{\text {th }}$ percentile values were 26, 26, 26 and 27, respectively.

For the brain healthy subgroup median values were 28, 29, 28 and 28. 
Comparisons for age-effects showed no differences when all individuals for each age group were compared. When only the individuals reaching 93 years of age were analysed, there was a significant lowering of MMSE in that age group (figure 4).

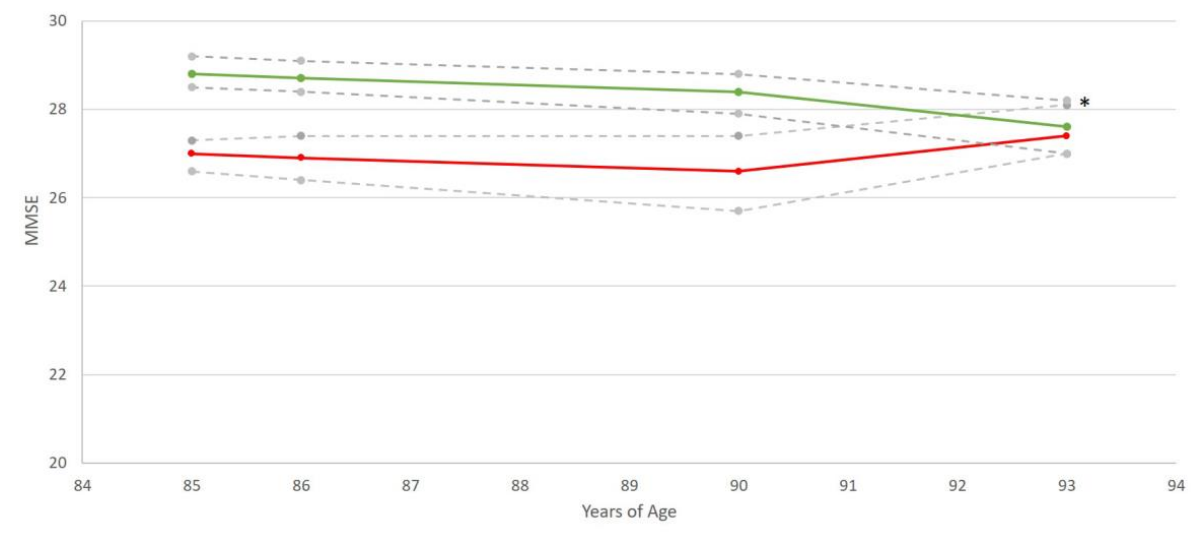

Figure 4. Lower: MMSE versus age for all individuals between 85 and 93 years of age, mean (95\% CI), p = 0.419, mixed models.

Upper: MMSE versus age for selected individuals $(n=50)$ who reached 93 years of age, mean (95\% CI), p = 0.003, mixed models. *Pairwise post-hoc comparisons showed that MMSE at 93 years of age was lower than the three earlier ages ( $\mathrm{p}<$ 0.037).

\section{Comments}

This study provides valuable information about normative MMSE data for the oldest in a population with high-education and relatively good socioeconomic status. This is of great importance from a PHC perspective where the majority of dementia investigations are in older people. Results fromlower-educated age cohorts suggest cut-offs of 21 for age 85 years and older, but the number of observations are quite few (125). An older Canadian study showed a mean MMSE of 25.9 and the the 25th percentile was 23 to 26 correlating to the education level (129). Alltogether the literature is variable and in clinical practice a low (24) MMSE cut-off is often used for possible cognitive impairment in old age.

However, in summary, our results, together with several previous studies including 85 year olds, suggest use of the $25^{\text {th }}$ percentile in MMSE of 25 to 26 points. Therefore, we conclude from the present data that MMSE 26 is as a reasonable cut-off for cognitive decline and further medical evaluation in older persons from 85 up to the age of 93 years. 
Our longitudinal data showed relatively stability over the 8-years study period. Comparisons for age-effects showed no differences when all individuals for each age group were compared. When only the individuals reaching 93 years of age $(n=50)$ were analysed there was a small but significant lowering of MMSE in that age group.

\section{Paper 4}

Together with the patient's history, medical examination and neuroimaging, cognitive testing is an important part of the basic dementia investigation. Aside from current recommendations to use MMSE and CDT, there is a great interest in other cognitive tests which can be used for dementia investigations, such as Cognistat and AQT. One modern example is the cognitive instrument MoCA, which in recent years has been introduced as a possible alternative, especially for detection of MCI and early dementia (77). Short versions of MoCA applicable for PHC has also been studied as an alternative (134). We do have normative values of MoCA results in Sweden but worldwide PHC data are scarce (76).

Another alternative is a more extensive neuropsychological assessment also for elderly people (135). The disadvantages are that the neuropsychological batteries are time consuming, possibly tiring for the oldest patients and the majority of the PHC settings often have a shortage in psychologists.

Cognitive Assessment Battery (CAB) was introduced as an instrument somewhere between short cognitive tests and more extensive neuropsychological assessments, and has been elaborated with the intention of sensitivity for early detection of cognitive decline (117). The CAB test consists of several domains and according to the instructions from Nordlund et al each subtest should be analysed separately using -2SD as cutoff for cognitive decline (117). A summarised assessment based on the overall picture of the results on all subtests must then be made to determine whether the patient is cognitively healthy, has MCI or dementia.

The main purpose was to evaluate the accuracy of the CAB test in a primary care population, based on routine clinical cases in a dementia investigations study across four PHC centres. Patients with cognitive symptoms as well as expected cognitively healthy patients were invited to participate. 


\section{Results}

Demographic data of test results in the two groups "cognitively non-impaired" and "cognitively impaired" showed the test results were significantly altered in the "cognitively impaired" group after adjustment for age and education.

The accuracy of the different subtests was analysed according to "no cognitive impairment" or "cognitive impairment" evaluated by the medical experts in the consensus discussion.

The results from the analysis of -2SD for cognitive decline according to Nordlund et al for 1,2 and 3 subtests are presented in table 6 . The result of the AUC varied from 0.685 to 0.772 .

Table 6. Receiver operation characteristics for subtests of significant deficits (-2 SD) in 1, 2, or 3 cognitive domains of the CAB test.

\begin{tabular}{ccc}
\hline $\begin{array}{c}\text { Number of domains } \\
\text { with significant } \\
\text { cognitive deficit }\end{array}$ & AUC & $\mathbf{9 5 \%} \mathbf{~ l ~}$ \\
\hline 1 & 0.772 & \\
2 & 0.748 & $0.661-0.883$ \\
3 & 0.685 & $0.639-0.857$ \\
& & $0.570-0.800$
\end{tabular}

When we analysed the numerical score for each subtest, instead of using the -2SD, the calculated AUC result was 0.643 to 0.884 , table 7 . This showed the highest AUC for the subtest Stroop 3 and the lowest AUC for Token test.

Table 7. Receiver operation characteristics (ROC) for subtests of CAB

\begin{tabular}{ccc}
\hline Test & AUC & $\mathbf{9 5 \%} \mathbf{C l}$ \\
\hline Delayed recall & 0.859 & $0.774-0.944$ \\
SDMT & 0.862 & $0.784-0.940$ \\
Naming & 0.837 & $0.784-0.925$ \\
CDT/Cube & 0.695 & $0.579-0.811$ \\
Token & 0.643 & $0.579-0.811$ \\
Stroop 3 & 0.884 & $0.807-0.960$ \\
\hline
\end{tabular}


We also produced a new possible model for analysis of $\mathrm{CAB}$, called CABsum. CABsum consists of the subtests that gives lower scores in case of impairment. Those subtests are delayed recall, SDMT, naming, CDT + Cube drawing and Token test. The range for the CABsum score results was 15106 (out of maximum 179 points). AUC for the CABsum was 0.916 (95\% CI 0.857-0.957) better than for the separate subtests analysed both numerically and using -2SD according to Nordlund et al. ROC analysis was performed comparing the CABsum and the MMSE scale data, figure 5 .
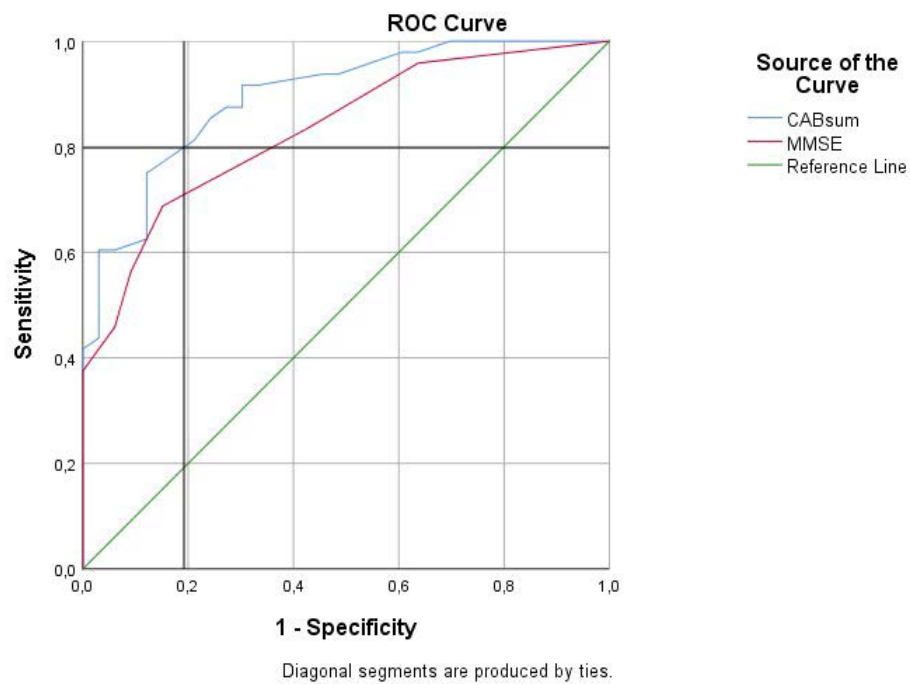

Figure 5. ROC curve MMSE vs CABsum.

\section{Comments}

The main purpose of this study was to evaluate the accuracy of CAB in dementia investigations in a primary care population. As the results to our knowledge are the first from a primary care setting, they contribute with valuable information.

Using the analysis method previously reported by Nordlund et al with the -2SD criteria on each subtest, the AUC outcome for cognitive impairment in 1,2 and 3 subtests was around 0.7 , corresponding to fairly good accuracy but with some poor subtest results $<0.7$. The time 20-30 minutes for performing $\mathrm{CAB}$ in primary care is quite substantial. This model of analysis also requires well-trained staff in primary care.

By introducing the CABsum the accuracy was increased and the AUC was high $>0.9$. We therefore highlight the possibility of using the numerical sum in clinical practice, a model easy applicable in primary care. However, 
it is necessary to take into consideration the risk of losing qualitative aspects when not looking separately at the results in each subtest.

Overall, the additive value of the $\mathrm{CAB}$ test in dementia investigations in PHC is not obvious. Besides questionable accuracy, the test is quite time consuming and normative values are scarce. Further studies are needed to ensure which is the best method for analysing the overall test result, CABsum being one possibility. An interesting aspect of this study is the ROC analysis which showed that the AUC of CABsum was superior to MMSE. 


\section{DISCUSSION}

The main finding of this thesis is that alternative cognitive tests, other than those in the current recommendation of MMSE in combination with CDT, are useful for basic dementia evaluations in PHC.

Normative values for elderly people are important for accurate dementia diagnosis in primary care investigations. Cognitively healthy older people perform well in MMSE. Using the result of the 25th percentile, we suggest MMSE 26 is a reasonable cut-off for cognitive decline and further medical evaluation in older persons from 85 to 93 years of age.

Both Cognistat and AQT improves the diagnostic accuracy with quite good sensitivity and acceptable specificity for PHC investigations as a complement to the MMSE. The use of CAB is more questionable in primary care settings.

A recent review in primary care advise against the use of MMSE in isolation to confirm or exclude a dementia diagnosis if the expected prevalence of disease in the population is quite high (132). In our PHC study, diagnostic cognitive testing was initiated in the case of cognitive symptoms and suspicion of possible dementia disease. Therefore, in a setting similar to ours, the prevalence of dementia disease is probably quite high and the conclusion above is supported by our results.

Meta-analysis of cognitive screening for MCI has reported AUC o.664 for MMSE and AUC 0.811 for MoCA, which can be compared to the MMSE data in our population with an AUC o.849 (136). This illustrates the challenge with finding consistent results when data originates from different populations. However, the aim of our study was not to find MCI in particular, instead the main purpose of the assessment was to diagnose or exclude a dementia disease.

It is necessary to keep in mind that the tests have their origins in different contexts and with different purposes. Therefore, it is not possible to compare the results directly without consideration of the context of the studies. MMSE evolved at a neurogeriatric ward of the hospital in the 1970s (97). Several new short tests are designed to screen specifically for MCI rather than dementia (136). The use of screening tests for MCI is controversial among GPs as the full value of active MCI case finding does not have a clear benefit for the primary care patient.

One reasonable question is whether GPs in primary care actively should look for MCI and pre-dementia conditions or not. In the absence of 
targeted treatment slowing down dementia disease progression, this is highly doubtful. Regarding the modifiable cardiovascular and metabolic risk factors, these are conditions already of high priority in PHC. However, the value of correct and early diagnosis of dementia disease is not controversial in primary care today. In the early dementia evaluation process there will be several patients receiving a new MCI diagnosis in need of follow up in the primary care system in the future. Of the tests in focus in this thesis, MMSE, AQT and Cognistat aim at detecting individuals with possible or rather probable dementia disease, while $\mathrm{CAB}$ was developed to diagnose MCI patients and individuals with early dementia disease.

\section{General findings}

\section{A Quick Test of Cognitive speed}

We present AQT as a usable cognitive test in dementia investigations in Swedish PHC, primarily as a complement to MMSE. AQT is brief, easily administrated and therefore applicable for primary care. AQT can be handled by GPs themselves or in team evaluations, making the test possible to distribute globally in different types of PHC systems.

AQT has been studied in different countries and the test is validated in several languages: Arabic, English, Greek, Japanese, Norwegian and Spanish, besides Swedish. A normative study of cognitively healthy older people (aged 45 to 90 years) in Italian primary care showed some age effect but only a weak correlation with education (109). The authors present age adjusted cut-off times for the AQT test based on +1 and +2 standard deviations in Italian language. In our study, we used the suggested cut off in the Swedish translated manual of 70 seconds in colour-form part three. Analysis of the ROC curve confirmed the cut-off time as reasonable in our complete study population.

In a Japanese population, AQT colour-form naming time correlated significantly with the Clinical Dementia Rating, the total score on the MiniMental State Examination, and the total score on the Neurobehavioral Cognitive Status (Cognistat) (113). The authors suggest AQT for use not only in moderate dementia diagnosis but also as a possible short test to discriminate between MCI and early $\mathrm{AD}$ versus cognitively healthy individuals. AQT has also been suggested as one way of distinguishing DLB from AD since relatively high MMSE results in combination with prolonged AQT time might indicate possible DLB (137). This is an example where the executive AQT test is as a good complement to the MMSE in the diagnostic process. However, data primarily strengthen AQT as an overall dementia 
diagnostic test and not for differential diagnosis. This is also how the test is recommended for use in Swedish primary care today.

Therefore, in our study we validated AQT in relation to any kind of cognitive impairment (a result below norms in any of the objective tests was categorised as cognitive impairment in the ROC analysis) including both MCI and dementia. The study population was too small to allow any subgroup analysis.

\section{Cognistat}

Our study results indicate that the relatively short multi-domain instrument Cognistat is applicable for dementia diagnosis in PHC. In summary, the most promising results were obtained when using the cut-off for cognitive decline in the minimum of one subtest. When the cut-off was increased (decline in two subtests or more) specificity was high but the sensitivity dropped to 0.57 with a risk of false negative results. NPV was also low 0.62 with increased risk of missing possible patients with cognitive decline in need of further investigation. Cognistat with the cut off one subtest showed a higher sensitivity, equal specificity and somewhat improved PPV in comparison with the combination MMSE and CDT currently recommended for basic dementia investigations in PHC.

The best AUC when comparing the different subtests of Cognistat was demonstrated for memory and construction. One disadvantage with Cognistat is the lack of a subtest for psychomotor speed. There are elements of executive functions in some of the subtests but a more specific subtest for executive ability is missing in the instrument. High cognitive reserve capacity has been associated with performance on semantic but not visuospatial tasks in both MCI and AD patients. Executive functions were only associated with high cognitive reserve capacity in patients with MCI and not dementia and is therefore of value in diagnosis in early stages of dementia (138).

One possibility for use of the multi-domain instrument Cognistat could be future interventional cognitive training based on patients' cognitive testing profile. As there are no available curative treatment for dementia disease, every intervention with a possibility of slowing down symptom progression is of interest. Data from cognitive training are incongruous but there are some indications of effect in early-stage AD patients (139). Improved knowledge of cognitive training is of importance in the planning of possible multi-professional interventions in $\mathrm{PHC}$ in the future. 
The result of better sensitivity is supported from previous studies comparing Cognistat and MMSE in geriatric elderly patients (140). The weakness in other studies has been low specificity and a low PPV; both are notably higher in our PHC population compared with hospitalised populations (141). To what extent Cognistat can be used for detection of early dementia disease and MCI is inconclusive according to previous results (106, 142).

Validation data on Cognistat in dementia diagnosis is overall quite scarce. Most of the research on the instrument has been done in the field of neurorehabilitation (143). It has been demonstrated that Cognistat is superior to MMSE in detecting cognitive deficits in patients with brain injury and psychiatry patients (141). To be even more conclusive regarding the use of Cognistat in dementia investigations, further studies in larger primary care populations would be desirable.

\section{Mini Mental Status Examination}

The median MMSE values for the entire population in our study over the ages 85,86 , 90, and 93 years was 28 for all ages investigated. The 25th percentile values were $26,26,26$ and 27 , respectively. In conclusion, we suggested MMSE 26 as a reasonable cut-off for cognitive decline and further medical evaluation in older persons from 85 to 93 years of age.

There is an increasing interest in the oldest-old (aged 90 and over) a rapid growing group in the population. The oldest are also of increased risk of developing dementia disease. Recently published data of eleven cognitive tests among 403 cognitively intact participants in California, aged 90 to 102, concluded significantly lower scores with increasing age on most tests (144). In the ELSA 85 population comparisons for age-effects showed no differences when all individuals for each age group were compared. When only the individuals reaching 93 years of age were analysed, there was a significant lowering of MMSE in that age group.

Previous studies worldwide have shown diverse MMSE results in elderly people. The diversity is highly dependent on differences in educational levels and socioeconomic presumptions. A recent normative study from China presented age-stratified normative values (145). Data presented as follows: The optimal cut-off points for dementia screening were $16 / 17$ for illiterate (sensitivity $87.6 \%$ and specificity $80.8 \%$ ), 19/20 for individuals with 1-6 years of education (sensitivity $93.6 \%$ and specificity 92.7\%), and 23/24 for individuals with seven or more years of education (sensitivity $94.3 \%$ and specificity $94.3 \%$ ) (145). 
However, the reported MMSE results in the study from California, with a similar population to the Sweden, was equivalent to ours (144). In the overall Californian study group, the mean MMSE value was 27.9. When analysing the age cohorts the mean results were as follows (age 90-91) 28, (age 92-94) 28.2, (age $\geq 95$ years) 27.4. The lowest 25th percentile value of MMSE was 26 in the overall cohort of elderly in all age groups. In an earlier Canadian study the 25th percentile was between 23 and 26 but in the similar education group compared to ours 25 points (129).

One interesting 3-year longitudinal Swedish study among very old people at the age of 97, 99 and 100 years showed that low MMSE results were associated with dementia also in the oldest old (146). There were no differences at baseline between those who developed dementia disease or not. MMSE scores were positively associated with education but not rate of decline when reaching the age of 100 years.

\section{Cognitive Assessment Battery}

The accuracy of the $\mathrm{CAB}$ test in a primary care population, based on routine clinical cases in PHC dementia investigations, were not convincing in our study. We used the norms of -2SD for cognitive decline according to Nordlund et al for 1, 2 and 3 subtests with varying AUC results in our study population from 0.685 to 0.772 (117). These AUC results are not so impressive regarding the time and resources required to use the $\mathrm{CAB}$ instrument in $\mathrm{PHC}$ investigations. The time needed to perform the $\mathrm{CAB}$ is around $20-30$ minutes, compared to brief instruments like AQT which takes around 5-10 minutes to conduct.

However, $\mathrm{CAB}$ was designed primarily for detection of MCI, an important aspect. In our study we investigated cognitive impairment with a suspicion of dementia disease overall in PHC. It is possible we would have found a better AUC if patients with indications and symptoms of moderate dementia would have been excluded.

Compared to other instruments available for MCI and early dementia diagnosis, for example CERAD and MoCA, accuracy for CAB seems to be worse. The original MoCA version has an AUC of 0.893 and the shorter MoCA versions by Roal et al and Wong et al demonstrated comparable AUC values of 88.4-88.9\% $(134,147,148)$. CERAD had an excellent AUC in one longitudinal PHC population but the result needs to be revalidated (91). To our knowledge the three tests has never been validated in the same population.

Analysis of the $\mathrm{CAB}$ instrument is somewhat complex for use in PHC, and it requires well-educated nurses, occupational therapists or neuropsychologist to avoid misinterpretions. This would of course be of value if the 
accuracy of the CAB AUC were above the shorter instruments available today, but this is doubtfully as AUC is in the similar range.

A total score has been suggested as a possible interpretation of CERAD. The CERAD total score was highly accurate in differentiating normal controls and $\mathrm{AD}$ individuals in a CERAD registry study (92). In independent samples, it could discriminate between cognitively healthy, MCI and AD patients. We constructed a CABsum from the subtests delayed recall, SDMT, naming, CDT + Cube drawing and Token test. AUC for the CABsum was 0.916 better than for the separate subtests analysed both numerically and for -2SD according to Nordlund et al. We suggest CABsum as a possibility for analysis but the results need revalidation in larger study populations both in PHC and memory clinics.

Data indicate a possibility to separate non-vascular MCI from vascular MCI with $\mathrm{CAB}$, which suggest decline in vascular MCI are more prominent in the subtests for memory, language and executive tests compared with non-vascular MCI patients, this is consistent with previous findings in $\mathrm{CAB}$ (118). As our study population was too small we have not been able to revalidate similar subgroup analyses.

\section{Methodological considerations}

\section{General strength and limitations}

Overall, there are relatively few studies of dementia cognitive testing conducted in a primary care setting as presented in studies I, II and IV. Often primary care dementia research is conducted in a specialist memory clinic with referred patients from PHC. For diagnostic instruments these studies need to be supplemented by research in the actual environment where the test is intended for use.

A greater methodological scope within the dissertation would have been desirable but the focus of the work has been on accuracy in clinical dementia diagnosis. Research which is needed in primary care.

The PHC population in studies I, II and IV is small with a limited number of participants both in the group with cognitive impairment as well as in the group with no cognitive impairment. Despite a long inclusion period, it was difficult to find participants. Patients who waived participation highlighted a fear of finding cognitive impairment they did not want to know about, or a feeling of stress with several tests and extra care visits. However, according to the statistical power calculation a minimum of 30 individuals per group would be sufficient to show differences between the groups. 
There was a tendency that cognitively healthy participants were easier to include among patients with higher education and socioeconomic security. This is reflected in the differences between the two groups with higher mean age and lower education in the group with cognitive impairment.

The prevalence of patients on antidepressant medication, salicylic acid, lipid-lowering drugs, and antihypertensive drugs was higher in the group with cognitive symptoms. The treatments are known to be associated with cognitive and metabolic conditions, possible risk factors for dementia disease, wherefore the differences are somewhat expected.

Longitudinal research over several years among elderly people is challenging. In the ELSA 85 population, a substantial number of the invited individuals did not enter the follow-up study at all. The postal questionnaire was sent to $n=650$ individuals born in 1922 in the municipality of Linköping. Finally, 374 actually proceeded and completed phase one. In the 5years follow-up, 119 (35\%) had died and at the age of 93 there were 51 remaining individuals in the cohort. The drop out due to age conditions such as frailty, diseases and fatigue was substantial between the follow-up points but a previous study in a similar elderly population showed the same trend (146).

Individuals living in sheltered homes were more often in the dropout group. Consequently, the study participants were probably healthier and had cognitive impairment to a lesser extent than the population in general. The risk of research bias in elderly population studies is well known and relevant to the ELSA 85 results as well. This is necessary to consider when implementing the suggested cut-off of 26 on MMSE. Our result is probably not usable everywhere, as the cut-off is suggested in the context of a quite healthy population, living at home, well educated and with moderate socioeconomic conditions. Nevertheless, these patients are commonly seen in PHC, making the results of the study highly relevant.

With increasing cultural diversity and growing elderly immigrant populations in Western European countries, the availability of brief cognitive screening instruments adequate for assessment of dementia in people from diverse backgrounds becomes increasingly important. AQT is an alternative but the multi-cultural tool RUDAS is of highest interest in this sense. Scandinavian data found RUDAS to have excellent diagnostic properties in a multicultural sample with a ROC area under the curve of 0.93 (149).

In all the studies in this thesis, fluency in speaking Swedish was an inclusion criterion, so that participants were able to understand the instructions and complete the tests. This is of course a limiting factor when implementing the results to a more diverse PHC population. 


\section{Statistical analyses}

\section{The receiver operating characteristic (ROC) curve}

Decision aids and diagnostic tests are often evaluated in terms of diagnostic testing parameters, such as the area under the receiver operating characteristic (ROC) curve, sensitivity and specificity. "Relative operating characteristic" is commonly used in diagnostic to distinguish between two classes of events. The outcome is, in theory, a precise and valid measure of diagnostic accuracy. The method is wide spread, not only in the medical field (medical test instruments, imaging) but also in other areas such as weather forecasting and information retrieval. ROC is also the focus of the statistical analysis in this thesis. However, the values on which the ROC-analysis is based is often of uncertain quality (121). Consequently, there are potential weaknesses also in ROC-analyses. One example being the uncertainty of the clinical diagnostic procedure and clinical diagnosis discussed earlier.

Clinicans want to know whether a condition is present, or not. Diagnostic tests can answer either yes/no (binary outcomes) or on a continuous scale. A ROC curve is obtained by tabulating all different values of sensitivity and specificity, then plotting sensitivity (true positive rate) on the y-axis against 1-specificity (false positive rate) on the $\mathrm{x}$-axis for the various values (150).

The area under the ROC curve (AUC) is a global measure of diagnostic tests ability to discriminate between whether a condition is present or not present. The AUC for a test is one value and is a commonly used measure for diagnostic accuracy overall. The AUC is an easy and applicable way to compare diagnostic accuracy between several studies for one particular diagnostic instrument or among comparable test instruments. Estimation of AUC relies on the knowledge of the true outcomes, and in clinical dementia diagnosis this is often based on gold standard evaluations with a risk of bias, especially in small samples as in our PHC study. There are published suggestions of new statistical methods for estimation of AUC under no ignorable verification bias (151). However, all the statistical methods used in the studies in the thesis were carefully discussed with a statistician.

\section{Cut-off values and the Youden index}

There is often an interest in finding the optimal threshold for a diagnostic test (cut-off). This value varies along the ROC curve. What is optimal depends on the subject of interest. It is necessary to weigh between false positive and false negative outcomes to determine if these are of equal im- 
portance or not, depending on the aim of the test. If these are of equal importance, the Youden index is reported (the value in the upper left quadrant of the ROC curve) (122). However, the Youden index is not always of the greatest interest

The optimal diagnostic tests have both high sensitivity and high specificity. In PHC, we do not want to miss patients with moderate or severe dementia disease and need brief instruments with high sensitivity (role in) applicable for that question. On the other hand, if the GP sees a patient with subjective memory concerns, suspected to have possible MCI, we need short instruments with high specificity (role out) to avoid false positive and minimise further unnecessary investigations. As a result, the optimal cutoff depends on several things: the patient, the clinical question, the test in use and the prevalence of the disease in the setting where the test is used.

For a brief instrument like the MMSE or AQT the importance of high sensitivity is probably superior to specificity in a PHC setting. This is primarily related to the gold standard diagnostic phenomena where clinicians usually evaluate patients with positive screening results further but not the patients with negative results. When using extensive instruments for dementia diagnosis in primary care, for example $\mathrm{CAB}$, both high sensitivity and specificity (and AUC value) are required, as these test results are often seen as conclusive for diagnosis by the GPs.

\section{Clinical Utility Index}

One way to describe the statistical results in a clinically relevant way is by analysing the CUI+ (the product of sensitivity and PPV), first mentioned in 2007 (123). CUI+ has been used in previous studies comparing brief cognitive tests (152). The main argument for using CUI+ is the possibility of weighing together a very high sensitivity where the prevalence of the tested phenomena perhaps is uncommon in the population. A test with a high sensitivity but low PPV and as a consequence a low CUI+, is of less interest to PHC. For an example, a condition with several symptoms may be highly connected to a disease and if we have a test looking for those symptoms, sensitivity of the test will become high. However, if that condition rarely exists in primary care and only presents in secondary care patients, the PPV will decrease due to the low prevalence and the CUI+ will be low. Under the described conditions, the test will be useful in secondary care but not in PHC.

CUI+ scores are possible to convert to qualitative grades (excellent, good, satisfactory and poor utility). CUI+ is only relevant when a positive result is under scrutiny as in the Cognistat analyses reported here. CUI+ for Cognistat in our study was good and superior to the recommended combination MMSE and CDT. This reinforces that the sub-domains of Cognistat are relevant for the patients with cognitive impairment seen in PHC. 


\section{Diagnostic considerations}

\section{Normative values and cut-offs for cognitive decline}

The conventional cut-off score for MMSE is <24 points (153). The use of cut-off $<27$ for cognitive impairment could be questioned, but in the ELSA 85 population the difference in MMSE results have earlier been shown to correspond well to differences in both IADL and health-related quality of life (154).

MMSE is best at measuring moderate dementia. A shift in one-step of the MMSE scale at different points does not correspond to equally big steps in decline in cognitive impairment (155). For early symptoms and MCI a more sensitive multi-domain instrument is needed; for low results different IADL measures are better suited.

MMSE is well-known to be highly affected by education levels and specific adjusted norms have been evaluated (129). When comparing MMSE (cutoff cognitive impairment <25) and RUDAS in a previous study the accuracy (AUC) was similar and RUDAS was not at all influenced by language, education or gender (156). The ELSA 85 from Linköping represents a population from a fairly well-educated area with relatively good socioeconomic conditions where the ceiling effects on MMSE are relatively low.

Cognistat is known to have ceiling effects due to high premorbid function with false negative results, although some data indicate quite good accuracy for MCI as well (157). However, there are normative data for elderly people, as ageing influences some components of construction, memory, and similarities (158). The cut-off point is age corrected for subjects aged 65-74 and 75-84 years. In our study, we used the cut-offs suggested in the manual.

$\mathrm{CAB}$ enl Nordlund et al is designed to find early cognitive decline. One limitation is that normative data are scarce and there is only one published study validating dementia and different subtypes (117). In our and otherprevious published data corrections for age and education have been necessary, suggesting a possible ceiling effect. This is needed to take into consideration in the clinic even when the -2SD norms for the subtests is used.

\section{Cognitive tests and driving ability in primary care}

The GP often must take into consideration patients' ability to drive a car safely in relation to possible cognitive decline. Questions about driving capacity is an important and sometimes difficult issue in dementia investiga- 
tions in PHC (159). The clinical assessment is often strengthened by cognitive testing. Both false negative and false positive test results can be devastating. As a GP, you do not want to miss an unsafe driver but on the other hand, you want to reinforce patients' capacity and autonomy for as long as possible.

MMSE results has been shown to correspond quite poorly to driving ability on driving tests, one further limitation when using the test alone in dementia evaluations. In theory executive tests and tests of psychomotor speed are of interest in relation to driving capacity. Studies looking at TMTA and -B total time had moderate discriminative abilities. Unfortunately, results indicate that the power of the TMT is the lowest where clinical physicians need it most (e.g. identifying CI patients whose driving skills have declined to an unsafe level) (160).

In one study with healthy young adults and matched individuals with Attention-Deficit/Hyperactivity Disorder (ADHD), AQT results revealed slower processing of visual stimuli in the ADHD group (161). The patients with ADHD also had more visual problems associated with driving than controls. Whether AQT can discriminate between driving capacity in patients with cognitive impairment is currently to our knowledge not described.

In PHC complementary specific driving tests and consultations with specialist clinics are often necessary when evaluating driving ability in early dementia, as the short tests do not give enough support for the decision. The $\mathrm{CAB}$ test includes subtests highlighted as more specific for driving evaluations (SDMT, Clox test, Stroop, TMT A, Rey Complex Figure and Pasmo). However, since there is a shortage and insecurity about the normative values for the driving purpose in the $\mathrm{CAB}$ driving subtests today, the usability for this specific question in PHC is limited.

In moderate and severe dementia the clinical symptoms are more obvious and often enough to recommend that the patient stop driving at the GP appointment after a team discussion.

\section{Diagnostic uncertainty and the gold standard}

Diagnoses in this PHC study were made from a team consensus discussion between the neuropsychologist and the geriatric specialist at the memory clinic. Aside from the clinical evaluation in PHC, the neuropsychologist and the geriatrician also had access to the results from the basic dementia instruments in PHC (MMSE and CDT) as well as the extended neuropsychological battery. The results from the test under investigation (AQT, Cognistat and $\mathrm{CAB}$ ) were blinded and not available in the team consensus discussion. 
This PHC study was conducted in a true clinical context with validation against the gold standard for basic dementia investigations in PHC. Due to the design, there is some familiar diagnostic uncertainty. Gold standard validation is especially challenging when the gold standard is a complex procedure (as in dementia diagnosis) and does not consist of one yes/no test. However, we tried to secure the diagnostic PHC process with an extended neuropsychological battery.

We know from previous studies that the correlation between clinical diagnosis and both neuroimaging and neuropathology is questionable in $\mathrm{AD}$ (162). There is also a substantial overlap between mixed Alzheimer's disease (AD) and vascular pathology in many patients (163). The cognitively healthy individuals were all evaluated by the neuropsychologist from the perspective of their premorbid condition. One possible way to strengthen the diagnosis would have been a follow-up after 1 year, for example with a review of the medical records or by re-visits and re-testing after 6 and 12 months. This is often recommended in gold standard validation studies but is not always feasible.

\section{Clinical implications}

We need better diagnostic instruments for detection of dementia in primary care. The results from this thesis cover an important knowledge gap in cognitive testing in dementia evaluations in PHC. Both AQT and Cognistat are available for testing in $\mathrm{PHC}$ today and implementation is possible with no delay. There is a need for further and more extensive studies and until then AQT and Cognistat are primarily a complement to MMSE.

Validation studies and accurate diagnosis in PHC is dependent on available normative values also for older people. Our data do not support the use of $\mathrm{CAB}$ in general in $\mathrm{PHC}$ dementia investigations, but the test might have a place in more extensive investigations in memory clinics.

It is necessary to increase the knowledge about and attention given to dementia and cognitive symptoms among patients and professionals in PHC. Delay to diagnosis by both patients and doctors needs to be diminished in the future.

Perhaps one way of working with diagnostic dementia instruments for GPs is to choose between several available instruments depending on the patient's symptoms. A recent review of validity of screening instruments for the detection of dementia and mild cognitive impairment in hospital inpatients was not able to recommend a single best instrument for use in 
the hospital setting (164). In primary care, we have a risk of under-diagnosis with the older instrument MMSE and a possible risk of over-diagnosis with newer MCI profiled instruments such as MoCA and different quick MCI screening tests. As in many other disease conditions, well worked diagnostic algorithms are probably helpful. Overall, it is important to work within the diagnostic process and follow-up care, with a patient-centred focus. Different collaborative care models have been shown to be successful (165).

This thesis highlights the need for multi-professional teams to be involved in dementia investigations. Better cognitive tests do not mean that the remaining part of the medical examination is less important. The testing is crucial but is only one piece of the diagnostic puzzle. Some short testing is possible for GPs to handle on their own in the clinic (for example MMSE and AQT) while tests such as Cognistat and MoCA need team diagnostic evaluations in PHC.

When older adults with dementia experience progressive functional decline, caregiver burden increases and finally nursing home placement is required. Family caregivers often become secondary patients due to the stress and cognitive strain, as physical and mental health has been shown to be slightly negatively associated with the burden of caregiving $(166,167)$. Early and correct diagnosis in PHC provides a possibility for generating coping strategies for both the patient and relatives and to increase important support from both social and health care services (168).

\section{Future issues}

In the western part of the world, patients will probably have a tendency to seek care with earlier symptoms of cognitive impairment. The first contact for the majority of patients with the health care system is primary care. Therefore, diagnostic instruments with the opportunity to detect early dementia and perhaps in the future mild cognitive impairment but also which are accurate enough for differential dementia diagnosis in $\mathrm{PHC}$ are of high interest and priority. One example for upcoming research is the MoCA instrument and future studies are needed to better validate the test and short MoCA versions in PHC. Further development of multi-domain instruments adapted for primary care would also be of value.

Ongoing research is looking for an easy and accurate laboratory blood test for the diagnosis of dementia. This is of course exciting and could be a reality in the future but currently this is far from normal clinical diagnostic procedures in $\mathrm{PCH}$. The area of neuroimaging is also under constant progress as a way of increasing dementia diagnostic accuracy. 
There is a great interest in digital diagnostic cognitive instruments and a rapid technical development is to be expected. Technical solutions open up opportunities for patients to test themselves for early cognitive symptoms. It also improves the possibility of correct follow-up of disease progression in the home environment with fewer resoures. However, in the follow-up of disease progression cognitive tests are one piece of the evaluation. Medical and functional assessments, activities of daily living and social support are equally fundamental for the patients and relatives.

A Korean study validated the use of MMSE-K in smartphones with 30 patients with ischemic or haemorrhagic stroke (169). The comparison showed good agreement between face-to-face and remote assessments, as well as between remote assessment and in-person collaborator evaluations regarding total MMSE-K score and subscores for each MMSE-K domain (orientation, memory, attention/calculation, language, and visuospatial function). Results from telephone-based cognitive screening through conversation with community-dwelling older adults has shown acceptable results in distinguishing dementia, but not MCI, from normal cognition (170). Future studies will be important for validation of technical instruments to secure accuracy and correct use of these new opportunities. To date, data from computer assessments among people with cognitive impairment are preliminary and quite scarce.

As the highest increase in people with dementia will be in developing countries, which have limited health care resources and capacity, brief cognitive tests for first evaluation will be important for a substantial time ahead. Since MMSE has a ceiling effect, other short instruments such as AQT and RUDAS which are better adapted for developing countries are of great importance.

With a global increase in elderly people, there is a need for more studies which examine diagnostic procedures, normative values and medication use and effects in the oldest population.

A great deal of pre-clinical research to find a way to prevent dementia is underway. So far, no one has succeeded. In the meantime, accurate diagnosis and overall good clinical care of people with dementia disease will be of great importance.

The Lancet Neurology Commission was formed with the overarching aim to provide information and expert recommendations about the growing problem of $\mathrm{AD}$ and related dementias of ageing. Among their key recommendations are, the importance of timely diagnosis and treatment, irrespective of social inequalities, to provide cost-effective care and preven- 
tive metabolic interventions in mid-life (171). Accurate and applicable cognitive tests and resources for dementia investigations and preventive care are essential for future primary care health systems. 


\section{CONCLUSIONS}

\section{General conclusion}

Alternative cognitive tests, aside from the current recommendation of the MMSE in combination with CDT, are useful for basic dementia evaluations in PHC. The conclusion is seen in the context of early cognitive testing conducted among individuals with objective cognitive symptoms and a suspicion of possible dementia. Good knowledge among general pracititioners of how to interpret the test results in the clinic is necessary. Normative values for the elderly people are important for accurate dementia diagnosis in primary care investigations.

\section{Specific conclusion}

AQT seems to be a usable test for dementia diagnosis in PHC. Sensitivity for AQT is equivalent to MMSE, and comparable to the combination MMSE and CDT. The AUC for AQT was 0.773. MMSE together with AQT shows promising results. AQT measures executive functions primarily and therefore gives important information in addition to the MMSE instrument.

The results indicate that Cognistat is applicable for dementia diagnosis in PHC with a relatively high sensitivity and PPV in combination with a rather good specificity and NPV. Cognistat is an easily administered multidomain instrument and is therefore interesting for dementia investigations in primary care. Memory and construction were the most sensitive subtests.

Cognitively healthy older people perform well in the MMSE. Median MMSE values for the total population over the ages 85, 86, 90, and 93 years was $28 / 30$ for all ages investigated. The $25^{\text {th }}$ percentile values were 26,26 , 26 and 27, respectively. From the results in the 25th percentile, we suggest MMSE 26 as a reasonable cut-off for cognitive decline and further medical evaluation in older persons from 85 to 93 years of age.

The additive value of the $\mathrm{CAB}$ test in dementia investigations in $\mathrm{PHC}$ is not obvious. Besides questionable accuracy, the test is quite time consuming and normative values are scarce. Introducing the CABsum increases the accuracy and is perhaps a simpler evaluation method for use in PHC but lacks qualitative aspects in the test analysis. 


\section{REFERENCES}

1. Blennow K, de Leon MJ, Zetterberg H. Alzheimer's disease. Lancet. 2006;368(9533):387-403.

2. Harvan JR, Cotter V. An evaluation of dementia screening in the primary care setting. J Am Acad Nurse Pract. 2006;18(8):351-60.

3. Brodaty H, Howarth GC, Mant A, Kurrle SE. General practice and dementia. A national survey of Australian GPs. The Medical journal of Australia. 1994;160(1):10-4.

4. Boise L, Camicioli R, Morgan DL, Rose JH, Congleton L. Diagnosing dementia: perspectives of primary care physicians. Gerontologist. 1999;39(4):457-64.

5. Iliffe S, Manthorpe J, Eden A. Sooner or later? Issues in the early diagnosis of dementia in general practice: a qualitative study. Fam Pract. 2003;20(4):376-81.

6. American Psychiatric Association, Ed., Diagnostic and Statistical Manual of Mental Disorders, Fifth Edition (DSM-V), American Psychiatric Association, Washington, DC, USA, 2013.

7. Lautenschlager NT, Almeida OP, Flicker L. Preventing dementia: why we should focus on health promotion now. Int Psychogeriatr. 2003;15(2):111-9.

8. Kivipelto M, Mangialasche F, Ngandu T. Lifestyle interventions to prevent cognitive impairment, dementia and Alzheimer disease. Nat Rev Neurol. 2018;14(11):653-66.

9. Clouston SAP, Smith DM, Mukherjee S, Zhang Y, Hou W, Link BG, et al. Education and cognitive decline: An integrative analysis of global longitudinal studies of cognitive aging. J Gerontol B Psychol Sci Soc Sci. 2019. 
10. Paulo AC, Sampaio A, Santos NC, Costa PS, Cunha P, Zihl J, et al. Patterns of cognitive performance in healthy ageing in Northern Portugal: a cross-sectional analysis. PLoS One. 2011;6(9):e24553.

11. Vårdanalys. Mf. VIP i vården? - Om utmaningar i vården av personer med kronisk sjukdom. Rapport 2014:2, ISBN 978-91-87213-24-3 http://www.vardanalys.se. 2014.

12. Global, regional, and national comparative risk assessment of 84 behavioural, environmental and occupational, and metabolic risks or clusters of risks, 1990-2016: a systematic analysis for the Global Burden of Disease Study 2016. Lancet. 2017;390(10100):1345-422.

13. Knight A, Bryan J, Murphy K. The Mediterranean diet and age-related cognitive functioning: A systematic review of study findings and neuropsychological assessment methodology. Nutritional neuroscience. 2017;20(8):449-68.

14. Sydenham E, Dangour AD, Lim WS. Omega 3 fatty acid for the prevention of cognitive decline and dementia. Cochrane Database Syst Rev. 2012(6):Cdoo5379.

15. Phillips MA, Childs CE, Calder PC, Rogers PJ. No Effect of Omega-3 Fatty Acid Supplementation on Cognition and Mood in Individuals with Cognitive Impairment and Probable Alzheimer's Disease: A Randomised Controlled Trial. International journal of molecular sciences. 2015;16(10):24600-13.

16. Eriksson MK, Franks PW, Eliasson M. A 3-year randomized trial of lifestyle intervention for cardiovascular risk reduction in the primary care setting: the Swedish Bjorknas study. PLoS One. 2009;4(4):e5195.

17. Lautenschlager NT, Cox KL, Flicker L, Foster JK, van Bockxmeer FM, Xiao J, et al. Effect of physical activity on cognitive function in older adults at risk for Alzheimer disease: a randomized trial. Jama. 2008;300(9):1027-37.

18. Najar J, Ostling S, Gudmundsson P, Sundh V, Johansson L, Kern S, et al. Cognitive and physical activity and dementia: A 44-year 
longitudinal population study of women. Neurology. 2019;92(12):e1322-e3o.

19. Kerse N, Elley CR, Robinson E, Arroll B. Is physical activity counseling effective for older people? A cluster randomized, controlled trial in primary care. J Am Geriatr Soc. 2005;53(11):1951-6.

20. Annear M, Lucas P, Wilkinson T, Shimizu Y. Prescribing physical activity as a preventive measure for middle-aged Australians with dementia risk factors. Australian journal of primary health. 2019;25(2):108-12.

21. Pulain $\mathrm{MH}$ A. Central Population Registers as a Source of Demographic Statistics in Europe. Population-E 2013; 68(2):183-212.

22. Religa D, Fereshtehnejad SM, Cermakova P, Edlund AK, GarciaPtacek S, Granqvist N, et al. SveDem, the Swedish Dementia Registry - a tool for improving the quality of diagnostics, treatment and care of dementia patients in clinical practice. PLoS One. 2015;10(2):e0116538.

23. Garre-Olmo J, Garcia-Ptacek S, Calvo-Perxas L, Turro-Garriga O, Lopez-Pousa S, Eriksdotter M. Diagnosis of Dementia in the Specialist Setting: A Comparison Between the Swedish Dementia Registry (SveDem) and the Registry of Dementias of Girona (ReDeGi). J Alzheimers Dis. 2016;53(4):1341-51.

24. Wimo A, Winblad B, Aguero-Torres H, von Strauss E. The magnitude of dementia occurrence in the world. Alzheimer Dis Assoc Disord. 2003;17(2):63-7.

25. Prince M, Bryce R, Albanese E, Wimo A, Ribeiro W, Ferri CP. The global prevalence of dementia: a systematic review and metaanalysis. Alzheimers Dement. 2013;9(1):63-75 e2.

26. WHO. Dementia: a public health priority. WHO, Geneva, Switzerland 2012 
27. Ferri CP, Prince M, Brayne C, Brodaty H, Fratiglioni L, Ganguli M, et al. Global prevalence of dementia: a Delphi consensus study. Lancet. 2005;366(9503):2112-7.

28. Langa KM, Larson EB, Crimmins EM, Faul JD, Levine DA, Kabeto MU, et al. A Comparison of the Prevalence of Dementia in the United States in 2000 and 2012. JAMA internal medicine. 2017;177(1):51-8.

29. Ponjoan A, Garre-Olmo J, Blanch J, Fages E, Alves-Cabratosa L, Marti-Lluch R, et al. Epidemiology of dementia: prevalence and incidence estimates using validated electronic health records from primary care. Clinical epidemiology. 2019;11:217-28.

30. Prince M. Methodological issues for population-based research into dementia in developing countries. A position paper from the 10/66 Dementia Research Group. Int J Geriatr Psychiatry. 2000;15(1):2130.

31. Statistics Sweden. Population statistics. http://www.scb.se/en.

32. Wimo A, Jonsson L, Fratiglioni L, Sandman PO, Gustavsson A, Skoldunger A, et al. The societal costs of dementia in Sweden 2012 relevance and methodological challenges in valuing informal care. Alzheimers Res Ther. 2016;8(1):59.

33. Wimo A, Guerchet M, Ali GC, Wu YT, Prina AM, Winblad B, et al. The worldwide costs of dementia 2015 and comparisons with 2010. Alzheimers Dement. 2017;13(1):1-7.

34. Olafsdottir M, Skoog I, Marcusson J. Detection of dementia in primary care: the Linkoping study. Dement Geriatr Cogn Disord. 2000;11(4):223-9.

35. Mitchell AJ, Shiri-Feshki M. Rate of progression of mild cognitive impairment to dementia--meta-analysis of 41 robust inception cohort studies. Acta Psychiatr Scand. 2009;119(4):252-65.

36. Petersen RC. Aging, mild cognitive impairment, and Alzheimer's disease. Neurologic clinics. 2000;18(4):789-806. 
37. Winblad B, Palmer K, Kivipelto M, Jelic V, Fratiglioni L, Wahlund LO, et al. Mild cognitive impairment--beyond controversies, towards a consensus: report of the International Working Group on Mild Cognitive Impairment. J Intern Med. 2004;256(3):240-6.

38. Gauthier S, Reisberg B, Zaudig M, Petersen RC, Ritchie K, Broich K, et al. Mild cognitive impairment. Lancet. 2006;367(9518):1262-70.

39. Rockwood K, Howard K, MacKnight C, Darvesh S. Spectrum of disease in vascular cognitive impairment. Neuroepidemiology. 1999;18(5):248-54.

40. Maioli F, Coveri M, Pagni P, Chiandetti C, Marchetti C, Ciarrocchi R, et al. Conversion of mild cognitive impairment to dementia in elderly subjects: a preliminary study in a memory and cognitive disorder unit. Archives of gerontology and geriatrics. 2007;44 Suppl 1:233-41.

41. Panza F, Frisardi V, Capurso C, D'Introno A, Colacicco AM, Imbimbo $\mathrm{BP}$, et al. Late-life depression, mild cognitive impairment, and dementia: possible continuum? Am J Geriatr Psychiatry. 2010;18(2):98-116.

42. Salthouse TA. Localizing age-related individual differences in a hierarchical structure. Intelligence. 2004;32(6).

43. Belleville S, Fouquet C, Hudon C, Zomahoun HTV, Croteau J. Neuropsychological Measures that Predict Progression from Mild Cognitive Impairment to Alzheimer's type dementia in Older Adults: a Systematic Review and Meta-Analysis. Neuropsychology review. 2017;27(4):328-53.

44. Roman GC. Vascular dementia: distinguishing characteristics, treatment, and prevention. J Am Geriatr Soc. 2003;51(5 Suppl Dementia):S296-304.

45. McKeith IG, Galasko D, Kosaka K, Perry EK, Dickson DW, Hansen LA, et al. Consensus guidelines for the clinical and pathologic diagnosis of dementia with Lewy bodies (DLB): report of the consortium on DLB international workshop. Neurology. 1996;47(5):1113-24. 
46. Swartling PG. [History of Swedish general practice]. Lakartidningen. 2006;103(24-25):1950-3.

47. Kringos DS, Boerma WG, Hutchinson A, van der Zee J, Groenewegen PP. The breadth of primary care: a systematic literature review of its core dimensions. BMC health services research. 2010;10:65.

48. Ranstad K, Midlov P, Halling A. Active listing and more consultations in primary care are associated with reduced hospitalisation in a Swedish population. BMC health services research. 2018;18(1):101.

49. Guerriero Austrom M, Damush TM, Hartwell CW, Perkins T, Unverzagt F, Boustani M, et al. Development and implementation of nonpharmacologic protocols for the management of patients with Alzheimer's disease and their families in a multiracial primary care setting. Gerontologist. 2004;44(4):548-53.

50. Callahan CM, Boustani MA, Unverzagt FW, Austrom MG, Damush TM, Perkins AJ, et al. Effectiveness of collaborative care for older adults with Alzheimer disease in primary care: a randomized controlled trial. Jama. 2006;295(18):2148-57.

51. Manthorpe J, Iliffe S, Eden A. Early recognition of dementia by nurses. J Adv Nurs. 2003;44(2):183-91.

52. Devoy S, Simpson EEA. Help-seeking intentions for early dementia diagnosis in a sample of Irish adults. Aging \& mental health. 2017;21(8):870-8.

53. Lee L, Hillier LM, Stolee P, Heckman G, Gagnon M, McAiney CA, et al. Enhancing dementia care: a primary care-based memory clinic. J Am Geriatr Soc. 2010;58(11):2197-204.

54. Lee L, Hillier LM, Molnar F, Borrie MJ. Primary Care Collaborative Memory Clinics: Building Capacity for Optimized Dementia Care. Healthcare quarterly (Toronto, Ont). 2017;19(4):55-62.

55. Lee L, Hillier LM, Locklin J, Lumley-Leger K, Molnar F. Specialist and family physician collaboration: Insights from primary care-based memory clinics. Health \& social care in the community. 2019. 
56. Lopponen M, Raiha I, Isoaho R, Vahlberg T, Kivela SL. Diagnosing cognitive impairment and dementia in primary health care -- a more active approach is needed. Age Ageing. 2003;32(6):606-12.

57. Ekdahl AW, Odzakovic E, Hellstrom I. Living Unnoticed: Cognitive Impairment in Older People with Multimorbidity. The journal of nutrition, health \& aging. 2016;20(3):275-9.

58. Sternberg SA, Wolfson C, Baumgarten M. Undetected dementia in community-dwelling older people: the Canadian Study of Health and Aging. J Am Geriatr Soc. 2000;48(11):1430-4.

59. Vassilas CA, Donaldson J. Telling the truth: what do general practitioners say to patients with dementia or terminal cancer? The British journal of general practice : the journal of the Royal College of General Practitioners. 1998;48(428):1081-2.

6o. Bradford A, Kunik ME, Schulz P, Williams SP, Singh H. Missed and delayed diagnosis of dementia in primary care: prevalence and contributing factors. Alzheimer Dis Assoc Disord. 2009;23(4):306-14.

61. van Hout H, Vernooij-Dassen M, Bakker K, Blom M, Grol R. General practitioners on dementia: tasks, practices and obstacles. Patient education and counseling. 2000;39(2-3):219-25.

62. Feldman HH, Jacova C, Robillard A, Garcia A, Chow T, Borrie M, et al. Diagnosis and treatment of dementia: 2. Diagnosis. CMAJ : Canadian Medical Association journal = journal de l'Association medicale canadienne. 2008;178(7):825-36.

63. De Lepeleire J, Aertgeerts B, Umbach I, Pattyn P, Tamsin F, Nestor L, et al. The diagnostic value of IADL evaluation in the detection of dementia in general practice. Aging \& mental health. 2004;8(1):52-7.

64. Socialstyrelsen. Nationella riktlinjer för vård och omsorg vid demenssjukdom. Stockholm, Sweden. 2017.

65. Boustani M, Peterson B, Hanson L, Harris R, Lohr KN. Screening for dementia in primary care: a summary of the evidence for the U.S. 
Preventive Services Task Force. Ann Intern Med. 2003;138(11):92737.

66. Ashford JW, Borson S, O'Hara R, Dash P, Frank L, Robert P, et al. Should older adults be screened for dementia? It is important to screen for evidence of dementia! Alzheimers Dement. 2007;3(2):7580.

67. Holsinger T, Deveau J, Boustani M, Williams JW, Jr. Does this patient have dementia? Jama. 2007;297(21):2391-404.

68. Trenkle DL, Shankle WR, Azen SP. Detecting cognitive impairment in primary care: performance assessment of three screening instruments. J Alzheimers Dis. 2007;11(3):323-35.

69. Brodaty H, Pond D, Kemp NM, Luscombe G, Harding L, Berman K, et al. The GPCOG: a new screening test for dementia designed for general practice. J Am Geriatr Soc. 2002;50(3):530-4.

70. Brodaty H, Connors MH, Loy C, Teixeira-Pinto A, Stocks N, Gunn J, et al. Screening for Dementia in Primary Care: A Comparison of the GPCOG and the MMSE. Dement Geriatr Cogn Disord. 2016;42(56):323-30.

71. Ramlall S, Chipps J, Bhigjee AI, Pillay BJ. The sensitivity and specificity of subjective memory complaints and the subjective memory rating scale, deterioration cognitive observee, mini-mental state examination, six-item screener and clock drawing test in dementia screening. Dement Geriatr Cogn Disord. 2013;36(1-2):11935 .

72. Amariglio RE, Townsend MK, Grodstein F, Sperling RA, Rentz DM. Specific subjective memory complaints in older persons may indicate poor cognitive function. J Am Geriatr Soc. 2011;59(9):1612-7.

73. Wang L, van Belle G, Crane PK, Kukull WA, Bowen JD, McCormick WC, et al. Subjective memory deterioration and future dementia in people aged 65 and older. J Am Geriatr Soc. 2004;52(12):2045-51. 
74. Astrand R, Rolstad S, Wallin A. Cognitive Impairment Questionnaire (CIMP-QUEST): reported topographic symptoms in MCI and dementia. Acta Neurol Scand. 2010;121(6):384-91.

75. Shankle WR, Romney AK, Hara J, Fortier D, Dick MB, Chen JM, et al. Methods to improve the detection of mild cognitive impairment. Proc Natl Acad Sci U S A. 2005;102(13):4919-24.

76. Borland E, Nagga K, Nilsson PM, Minthon L, Nilsson ED, Palmqvist S. The Montreal Cognitive Assessment: Normative Data from a Large Swedish Population-Based Cohort. J Alzheimers Dis. 2017;59(3):893901.

77. Nasreddine ZS, Phillips NA, Bedirian V, Charbonneau S, Whitehead V, Collin I, et al. The Montreal Cognitive Assessment, MoCA: a brief screening tool for mild cognitive impairment. J Am Geriatr Soc. 2005;53(4):695-9.

78. Clarnette R, O'Caoimh R, Antony DN, Svendrovski A, Molloy DW. Comparison of the Quick Mild Cognitive Impairment (Qmci) screen to the Montreal Cognitive Assessment (MoCA) in an Australian geriatrics clinic. Int J Geriatr Psychiatry. 2017;32(6):643-9.

79. Wang J, Logovinsky V, Hendrix SB, Stanworth SH, Perdomo C, Xu L, et al. ADCOMS: a composite clinical outcome for prodromal Alzheimer's disease trials. $J$ Neurol Neurosurg Psychiatry. 2016;87(9):993-9.

80. Ross-Swain D, Wiig EH. Reductions in 'Ross Information Processing Test-Geriatric' information processing and 'A Quick Test of Cognitive Speed' processing speed in Alzheimer's disease: which lead and which follow? Int J Rehabil Res. 2008;31(1):81-4.

81. Arbuthnott K, Frank J. Trail making test, part B as a measure of executive control: validation using a set-switching paradigm. J Clin Exp Neuropsychol. 2000;22(4):518-28. 
82. Cangoz B, Karakoc E, Selekler K. Trail Making Test: normative data for Turkish elderly population by age, sex and education. J Neurol Sci. 2009;283(1-2):73-8.

83. Bastug G, Ozel-Kizil ET, Sakarya A, Altintas O, Kirici S, Altunoz U. Oral trail making task as a discriminative tool for different levels of cognitive impairment and normal aging. Arch Clin Neuropsychol. 2013;28(5):411-7.

84. Golden CJ, Hammeke TA, Purisch AD. Diagnostic validity of a standardized neuropsychological battery derived from Luria's neuropsychological tests. J Consult Clin Psychol. 1978;46(6):1258-65.

85. Troyer AK, Leach L, Strauss E. Aging and response inhibition: Normative data for the Victoria Stroop Test. Neuropsychol Dev Cogn B Aging Neuropsychol Cogn. 2006;13(1):20-35.

86. Vendrell P, Junque C, Pujol J, Jurado MA, Molet J, Grafman J. The role of prefrontal regions in the Stroop task. Neuropsychologia. 1995;33(3):341-52.

87. Wiig EH, Nielsen NP, Minthon L, McPeek D, Said K, Warkentin S. Parietal lobe activation in rapid, automatized naming by adults. Percept Mot Skills. 2002;94(3 Pt 2):1230-44.

88. Naqvi RM, Haider S, Tomlinson G, Alibhai S. Cognitive assessments in multicultural populations using the Rowland Universal Dementia Assessment Scale: a systematic review and meta-analysis. CMAJ : Canadian Medical Association journal = journal de l'Association medicale canadienne. 2015;187(5):E169-75.

89. Traykov L, Baudic S, Raoux N, Latour F, Rieu D, Smagghe A, et al. Patterns of memory impairment and perseverative behavior discriminate early Alzheimer's disease from subcortical vascular dementia. J Neurol Sci. 2005;229-230:75-9.

90. Levy JA, Chelune GJ. Cognitive-behavioral profiles of neurodegenerative dementias: beyond Alzheimer's disease. J Geriatr Psychiatry Neurol. 2007;20(4):227-38. 
91. Wolfsgruber S, Jessen F, Wiese B, Stein J, Bickel H, Mosch E, et al. The CERAD neuropsychological assessment battery total score detects and predicts Alzheimer disease dementia with high diagnostic accuracy. Am J Geriatr Psychiatry. 2014;22(10):1017-28.

92. Chandler MJ, Lacritz LH, Hynan LS, Barnard HD, Allen G, Deschner $\mathrm{M}$, et al. A total score for the CERAD neuropsychological battery. Neurology. 2005;65(1):102-6.

93. WHO. The ICD-10 International Classification, 2007. World Health Organization, Geneva, Switzerland, 2007.

94. McKhann G, Drachman D, Folstein M, Katzman R, Price D, Stadlan EM. Clinical diagnosis of Alzheimer's disease: report of the NINCDSADRDA Work Group under the auspices of Department of Health and Human Services Task Force on Alzheimer's Disease. Neurology. 1984;34(7):939-44.

95. Reiman EM, McKhann GM, Albert MS, Sperling RA, Petersen RC, Blacker D. Clinical impact of updated diagnostic and research criteria for Alzheimer's disease. J Clin Psychiatry. 2011;72(12):e37.

96. Emre M, Aarsland D, Brown R, Burn DJ, Duyckaerts C, Mizuno Y, et al. Clinical diagnostic criteria for dementia associated with Parkinson's disease. Mov Disord. 2007;22(12):1689-707; quiz 837.

97. Folstein MF, Folstein SE, McHugh PR. "Mini-mental state". A practical method for grading the cognitive state of patients for the clinician. J Psychiatr Res. 1975;12(3):189-98.

98. Folstein M, Folstein S, McHugh P, Fanjiang G, Odessa F. Mini-Mental State Examination user's guide. Odessa FL: Psychological Assessment Resources. 2001.

99. Libon DJ, Malamut BL, Swenson R, Sands LP, Cloud BS. Further analyses of clock drawings among demented and nondemented older subjects. Arch Clin Neuropsychol. 1996;11(3):193-205. 
100. Suhr J, Grace J, Allen J, Nadler J, McKenna M. Quantitative and qualitative performance of stroke versus normal elderly on six clock drawing systems. Arch Clin Neuropsychol. 1998;13(6):495-502.

101. Lee DY, Seo EH, Choo IH, Kim SG, Lee JS, Lee DS, et al. Neural correlates of the Clock Drawing Test performance in Alzheimer's disease: a FDG-PET study. Dement Geriatr Cogn Disord. 2008;26(4):306-13.

102. Palmqvist S. Validation of brief cognitive tests in mild cognitive impairment, Alzheimer's disease and dementia with Lewy bodies. Clinical Memory research Unit. Department of Clinical Sciences. Faculty of Medicine. Lund University. 2011.

103. Shulman KI. Clock-drawing: is it the ideal cognitive screening test? Int J Geriatr Psychiatry. 2000;15(6):548-61.

104. Nokleby K, Boland E, Bergersen H, Schanke AK, Farner L, Wagle J, et al. Screening for cognitive deficits after stroke: a comparison of three screening tools. Clin Rehabil. 2008;22(12):1095-104.

105. Kiernan RJ, Mueller J, Langston JW, Van Dyke C. The Neurobehavioral Cognitive Status Examination: a brief but quantitative approach to cognitive assessment. Ann Intern Med. 1987;107(4):481-5.

106. Matsuda O, Saito M. Multiple cognitive deficits in patients during the mild cognitive impairment stage of Alzheimer's disease: how are cognitive domains other than episodic memory impaired? Int Psychogeriatr. 2009;21(5):970-6.

107. Caneman, G. Manual Cognistat - NKSU (in Swedish). 2001.

108. Nielsen NP, Wiig EH, Warkentin S, Minthon L. Clinical utility of colorform naming in Alzheimer's disease: preliminary evidence. Percept Mot Skills. 2004;99(3 Pt 2):1201-4.

109. Petrazzuoli F, Palmqvist S, Thulesius H, Buono N, Pirrotta E, Cuffari A, et al. A Quick Test of Cognitive Speed: norm-referenced criteria for 121 Italian adults aged 45 to 90 years. Int Psychogeriatr. 2014:1-8. 
110. Wiig EH, Nielsen NP, Jacobson JM. A Quick Test of Cognitive Speed: patterns of age groups 15 to 95 years. Percept Mot Skills. 2007;104(3 Pt 2):1067-75.

111. Nielsen NP, Wiig EH. Alzheimer's Quick Test cognitive screening criteria for West African speakers of Krio. Age Ageing. 2006;35(5):503-7.

112. Subirana-Mirete J, Bruna O, Virgili C, Signo S, Palma C. Processing speed in the aging process: screening criteria for the Spanish Quick Test of Cognitive Speed. Percept Mot Skills. 2014;119(2):417-29.

113. Takahashi F, Awata S, Sakuma N, Inagaki H, Ijuin M. Reliability and validity of A Quick Test of Cognitive Speed for detecting early-stage dementia in elderly Japanese. Psychogeriatrics. 2012;12(2):75-82.

114. Wiig, EH, Nielsen, NP, Minthon, L, Warkentin, S. AQT: A Quick Test of Cognitive Speed. San Antonio, TX: Pearson, 2002.

115. Nielsen NP, Wiig EH. An additive model for relations between AQT single- and dual-dimension naming speed. Percept Mot Skills. 2011;112(2):499-508.

116. Park S, Pyo S, Shin SA, Lee JY, Kim YK, Park HJ, et al. A quick test of cognitive speed in older adults with Alzheimer's disease and mild cognitive impairment: A preliminary behavioral and brain imaging study. Psychiatry Res Neuroimaging. 2018;280:30-8.

117. Nordlund A, Pahlsson L, Holmberg C, Lind K, Wallin A. The Cognitive Assessment Battery (CAB): a rapid test of cognitive domains. Int Psychogeriatr. 2011;23(7):1144-51.

118. Nystrom O, Wallin A, Nordlund A. MCI of different etiologies differ on the Cognitive Assessment Battery. Acta Neurol Scand. 2015;132(1):31-6.

119. Holland R, Smith RD, Harvey I, Swift L, Lenaghan E. Assessing quality of life in the elderly: a direct comparison of the EQ-5D and AQoL. Health economics. 2004;13(8):793-805. 
120. Wolfs CA, Dirksen CD, Kessels A, Willems DC, Verhey FR, Severens JL. Performance of the EQ-5D and the EQ-5D+C in elderly patients with cognitive impairments. Health and quality of life outcomes. 2007;5:33.

121. Swets JA. Measuring the accuracy of diagnostic systems. Science. 1988;240(4857):1285-93.

122. Fluss R, Faraggi D, Reiser B. Estimation of the Youden Index and its associated cutoff point. Biometrical journal Biometrische Zeitschrift. 2005;47(4):458-72.

123. Mitchell AJ. Sensitivity $x$ PPV is a recognized test called the clinical utility index (CUI+). European journal of epidemiology. 2011;26(3):251-2; author reply 2.

124. Waldorff FB, Rishoj S, Waldemar G. Identification and diagnostic evaluation of possible dementia in general practice. A prospective study. Scand J Prim Health Care. 2005;23(4):221-6.

125. Crum RM, Anthony JC, Bassett SS, Folstein MF. Population-based norms for the Mini-Mental State Examination by age and educational level. JAMA. 1993;269(18):2386-91.

126. Mitchell AJ. A meta-analysis of the accuracy of the mini-mental state examination in the detection of dementia and mild cognitive impairment. J Psychiatr Res. 2009;43(4):411-31.

127. American Psychiatric Association, Ed., Diagnostic and Statistical Manual of Mental Disorders, Foruth Edition (DSM-IV), American Psychiatric Association, Washington, DC, USA, 2004

128. Nakata E, Kasai M, Kasuya M, Akanuma K, Meguro M, Ishii H, et al. Combined memory and executive function tests can screen mild cognitive impairment and converters to dementia in a community: the Osaki-Tajiri project. Neuroepidemiology. 2009;33(2):103-10.

129. Bravo G, Hebert R. Age- and education-specific reference values for the Mini-Mental and modified Mini-Mental State Examinations 
derived from a non-demented elderly population. Int $\mathrm{J}$ Geriatr Psychiatry. 1997;12(10):1008-18.

130. Kirby M, Denihan A, Bruce I, Coakley D, Lawlor BA. The clock drawing test in primary care: sensitivity in dementia detection and specificity against normal and depressed elderly. Int $\mathrm{J}$ Geriatr Psychiatry. 2001;16(10):935-40.

131. National Collaborating Centre for Mental H. National Institute for Health and Clinical Excellence: Guidance. Dementia: A NICE-SCIE Guideline on Supporting People With Dementia and Their Carers in Health and Social Care. Leicester (UK): British Psychological Society The British Psychological Society \& The Royal College of Psychiatrists.; 2007.

132. Creavin ST, Wisniewski S, Noel-Storr AH, Trevelyan CM, Hampton T, Rayment D, et al. Mini-Mental State Examination (MMSE) for the detection of dementia in clinically unevaluated people aged 65 and over in community and primary care populations. Cochrane Database Syst Rev. 2016(1):CDo11145.

133. Skoog I, Borjesson-Hanson A, Kern S, Johansson L, Falk H, Sigstrom $\mathrm{R}$, et al. Decreasing prevalence of dementia in 85-year olds examined 22 years apart: the influence of education and stroke. Scientific reports. 2017;7(1):6136.

134. Liew TM. The Optimal Short Version of Montreal Cognitive Assessment in Diagnosing Mild Cognitive Impairment and Dementia. Journal of the American Medical Directors Association. 2019.

135. Wong CG, Thomas KR, Edmonds EC, Weigand AJ, Bangen KJ, Eppig JS, et al. Neuropsychological Criteria for Mild Cognitive Impairment in the Framingham Heart Study's Old-Old. Dement Geriatr Cogn Disord. 2018;46(5-6):253-65.

136. Breton A, Casey D, Arnaoutoglou NA. Cognitive tests for the detection of mild cognitive impairment (MCI), the prodromal stage of dementia: 
Meta-analysis of diagnostic accuracy studies. Int J Geriatr Psychiatry. 2019;34(2):233-42.

137. Andersson M, Wiig EH, Minthon L, Londos E. A Quick Test for Cognitive Speed: a measure of cognitive speed in dementia with Lewy bodies. Am J Alzheimers Dis Other Demen. 2007;22(4):313-8.

138. Darby RR, Brickhouse M, Wolk DA, Dickerson BC. Effects of cognitive reserve depend on executive and semantic demands of the task. $\mathrm{J}$ Neurol Neurosurg Psychiatry. 2017;88(9):794-802.

139. Nousia A, Siokas V, Aretouli E, Messinis L, Aloizou AM, Martzoukou M, et al. Beneficial Effect of Multidomain Cognitive Training on the Neuropsychological Performance of Patients with Early-Stage Alzheimer's Disease. Neural Plast. 2018;2018:2845176.

140. Fields SD, Fulop G, Sachs CJ, Strain J, Fillit H. Usefulness of the Neurobehavioral Cognitive Status Examination in the hospitalized elderly. Int Psychogeriatr. 1992;4(1):93-102.

141. Lamarre CJ, Patten SB. A clinical evaluation of the Neurobehavioral Cognitive Status Examination in a general psychiatric inpatient population. J Psychiatry Neurosci. 1994;19(2):103-8.

142. Johansson M, Wressle E. Validation of the neurobehavioral cognitive status examination and the Rivermead Behavioural Memory Test in investigations of dementia. Scand J Occup Ther. 2012;19(3):282-7.

143. Chan SC, Chan CC, Wu Y, Liu KP, Xu YW. Differentiating cognitive functions of poststroke patients with specific brain lesions: A preliminary study on the clinical utility of Cognistat-P. Appl Neuropsychol Adult. 2016;23(4):274-83.

144. Melikyan ZA, Corrada MM, Dick MB, Whittle C, Paganini-Hill A, Kawas CH. Neuropsychological Test Norms in Cognitively Intact Oldest-Old. J Int Neuropsychol Soc. 2019;25(5):530-45.

145. Li H, Jia J, Yang Z. Mini-Mental State Examination in Elderly Chinese: A Population-Based Normative Study. J Alzheimers Dis. 2016;53(2):487-96. 
146. Skoog J, Backman K, Ribbe M, Falk H, Gudmundsson P, Thorvaldsson V, et al. A Longitudinal Study of the Mini-Mental State Examination in Late Nonagenarians and Its Relationship with Dementia, Mortality, and Education. $J$ Am Geriatr Soc. 2017;65(6):1296-300.

147. Roalf DR, Moore TM, Wolk DA, Arnold SE, Mechanic-Hamilton D, Rick J, et al. Defining and validating a short form Montreal Cognitive Assessment (s-MoCA) for use in neurodegenerative disease. J Neurol Neurosurg Psychiatry. 2016;87(12):1303-10.

148. Wong A, Law LS, Liu W, Wang Z, Lo ES, Lau A, et al. Montreal Cognitive Assessment: One Cutoff Never Fits All. Stroke. 2015;46(12):3547-50.

149. Nielsen TR, Segers K, Vanderaspoilden V, Bekkhus-Wetterberg P, Bjorklof GH, Beinhoff U, et al. Validation of the Rowland Universal Dementia Assessment Scale (RUDAS) in a multicultural sample across five Western European countries: diagnostic accuracy and normative data. Int Psychogeriatr. 2019;31(2):287-96.

150. Hoo ZH, Candlish J, Teare D. What is an ROC curve? Emerg Med J. 2017;34(6):357-9.

151. Yu W, Kim JK, Park T. Estimation of Area Under the ROC Curve under nonignorable verification bias. Stat Sin. 2018;28(4):2149-66.

152. Goncalves DC, Arnold E, Appadurai K, Byrne GJ. Case finding in dementia: comparative utility of three brief instruments in the memory clinic setting. Int Psychogeriatr. 2011;23(5):788-96.

153. Tombaugh TN, McIntyre NJ. The mini-mental state examination: a comprehensive review. J Am Geriatr Soc. 1992;40(9):922-35.

154. Johansson MM, Marcusson J, Wressle E. Cognition, daily living, and health-related quality of life in 85-year-olds in Sweden. Neuropsychol Dev Cogn B Aging Neuropsychol Cogn. 2012;19(3):421-32. 
155. Mungas D, Reed BR. Application of item response theory for development of a global functioning measure of dementia with linear measurement properties. Stat Med. 2000;19(11-12):1631-44.

156. Rowland JT, Basic D, Storey JE, Conforti DA. The Rowland Universal Dementia Assessment Scale (RUDAS) and the Folstein MMSE in a multicultural cohort of elderly persons. Int Psychogeriatr. 2006;18(1):111-20.

157. Nesset M, Kersten H, Ulstein ID. Brief Tests such as the Clock Drawing Test or Cognistat Can Be Useful Predictors of Conversion from MCI to Dementia in the Clinical Assessment of Outpatients. Dement Geriatr Cogn Dis Extra. 2014;4(2):263-70.

158. Tsuruoka Y, Takahashi M, Suzuki M, Sato K, Shirayama Y. Utility of the Neurobehavioral Cognitive Status Examination (COGNISTAT) in differentiating between depressive states in late-life depression and late-onset Alzheimer's disease: a preliminary study. Ann Gen Psychiatry. 2016;15:3.

159. Piersma D, Fuermaier ABM, de Waard D, De Deyn PP, Davidse RJ, de Groot J, et al. The MMSE should not be the sole indicator of fitness to drive in mild Alzheimer's dementia. Acta Neurol Belg. 2018;118(4):637-42.

16o. Dobbs BM, Shergill SS. How effective is the Trail Making Test (Parts A and B) in identifying cognitively impaired drivers? Age Ageing. 2013;42(5):577-81.

161. Kim S, Chen S, Tannock R. Visual function and color vision in adults with Attention-Deficit/Hyperactivity Disorder. J Optom. 2014;7(1):22-36.

162. Knopman DS, DeKosky ST, Cummings JL, Chui H, Corey-Bloom J, Relkin N, et al. Practice parameter: diagnosis of dementia (an evidence-based review). Report of the Quality Standards Subcommittee of the American Academy of Neurology. Neurology. 2001;56(9):1143-53. 
163. Libon DJ, Drabick DA, Giovannetti T, Price CC, Bondi MW, Eppig J, et al. Neuropsychological syndromes associated with Alzheimer's/vascular dementia: a latent class analysis. J Alzheimers Dis. 2014;42(3):999-1014.

164. Hwang AB, Boes S, Nyffeler T, Schuepfer G. Validity of screening instruments for the detection of dementia and mild cognitive impairment in hospital inpatients: A systematic review of diagnostic accuracy studies. PLoS One. 2019;14(7):e0219569.

165. Dreier-Wolfgramm A, Michalowsky B, Austrom MG, van der Marck MA, Iliffe S, Alder C, et al. Dementia care management in primary care : Current collaborative care models and the case for interprofessional education. Z Gerontol Geriatr. 2017;50(Suppl 2):68-77.

166. Vitaliano PP, Zhang J, Scanlan JM. Is caregiving hazardous to one's physical health? A meta-analysis. Psychol Bull. 2003;129(6):946-72.

167. Caswell LW, Vitaliano PP, Croyle KL, Scanlan JM, Zhang J, Daruwala A. Negative associations of chronic stress and cognitive performance in older adult spouse caregivers. Exp Aging Res. 2003;29(3):303-18.

168. Mclaren AN, Lamantia MA, Callahan CM. Systematic review of nonpharmacologic interventions to delay functional decline in community-dwelling patients with dementia. Aging \& mental health. 2013;17(6):655-66.

169. Park HY, Jeon SS, Lee JY, Cho AR, Park JH. Korean Version of the Mini-Mental State Examination Using Smartphone: A Validation Study. Telemed J E Health. 2017;23(10):815-21.

170. Bentvelzen AC, Crawford JD, Theobald A, Maston K, Slavin MJ, Reppermund S, et al. Validation and Normative Data for the Modified Telephone Interview for Cognitive Status: The Sydney Memory and Ageing Study. J Am Geriatr Soc. 2019.

171. Winblad B, Amouyel P, Andrieu S, Ballard C, Brayne C, Brodaty H, et al. Defeating Alzheimer's disease and other dementias: a priority for European science and society. Lancet Neurol. 2016;15(5):455-532. 


\section{Papers}

The papers associated with this thesis have been removed for copyright reasons. For more details about these see:

http://urn.kb.se/resolve?urn=urn:nbn:se:liu:diva-160371 


\title{
FACULTY OF MEDICINE AND HEALTH SCIENCES
}

\author{
Linköping Medical Dissertations No. 1691, 2019 \\ Department of Medical and Health Sciences \\ Linköping University \\ SE-581 83 Linköping, Sweden
}

www.liu.se 